\title{
Forecasting Vegetation Condition with a Bayesian Auto-regressive Distributed Lags (BARDL) Model
}

\author{
Edward E. Salakpi ${ }^{1}$, Peter D. Hurley ${ }^{1,2}$, James M. Muthoka ${ }^{3}$, Adam B. Barrett ${ }^{4}$, Andrew Bowell ${ }^{1,2}$, Seb \\ Oliver $^{1,2}$, and Pedram Rowhani ${ }^{3}$ \\ ${ }^{1}$ The Data Intensive Science Centre, Department of Physics and Astronomy, University of Sussex, Brighton BN1 9QH, UK \\ ${ }^{2}$ Astronomy Centre, Department of Physics and Astronomy, University of Sussex, Brighton BN1 9QH, UK \\ ${ }^{3}$ Department of Geography, School of Global Studies, University of Sussex, Brighton BN1 9QJ, UK \\ ${ }^{4}$ Sackler Centre for Consciousness Science, Department of Informatics, University of Sussex, Brighton BN1 9QJ, UK
}

Correspondence: Edward E. Salakpi (e.salakpi@sussex.ac.uk)

\begin{abstract}
Droughts form a large part of climate/weather-related disasters reported globally. In Africa, pastoralists living in the Arid and Semi-Arid Lands (ASALs) are the worse affected. Prolonged dry spells that cause vegetation stress in these regions have resulted in the loss of income and livelihoods. To curb this, global initiatives like the Paris Agreement and the United Nations recognised the need to establish Early Warning Systems (EWS) to save lives and livelihoods. Existing EWS use a combination of Satellite Earth Observation (EO) based biophysical indicators like the Vegetation Condition Index (VCI) and socio-economic factors to measure and monitor droughts. Most of these EWS rely on expert knowledge in estimating upcoming drought conditions without using forecast models. Recent research has shown that the use of robust algorithms like Auto-Regression, Gaussian Processes and Artificial Neural Networks can provide very skilled models for forecasting vegetation condition at short to medium range lead times. However, to enable preparedness for early action, forecasts with a longer lead time are needed. The objective of this research work is to develop models that forecast vegetation conditions at longer lead times on the premise that vegetation condition is controlled by factors like precipitation and soil moisture. To achieve this, we used a Bayesian Auto-Regressive Distributed Lag (BARDL) modelling approach which enabled us to factor in lagged information from Precipitation and Soil moisture levels into our VCI forecast model. The results showed a $\sim 2$-week gain in the forecast range compared to the univariate $\mathrm{AR}$ model used as a baseline. The $R^{2}$ scores for the Bayesian ARDL model were $0.94,0.85$ and 0.74 , compared to the AR model's $R^{2}$ of $0.88,0.77$ and 0.65 for 6,8 and 10 weeks lead time respectively.
\end{abstract}

\section{Introduction}

Drought events are amongst the most prevalent natural disasters reported globally and affect some 10 million people annually (Deleersnyder, 2018). In Africa, the devastating effects of droughts are mostly seen in the Arid and Semi-Arid Lands (ASALs), where people's lives and livelihoods mostly depend on agro-pastoral activities (Gebremeskel et al., 2019). Pastoralism in these regions contributes immensely to food security and local economies (Vatter, 2019). However, the ASALs grass- and shrublands, which serve as the main source of fodder for the livestock are among the first to be hit by low rains and extreme temperature 
(FAO, 2018). These dry spells, when prolonged, adversely impact the food markets, income, and eventually leads to the loss of livelihoods (FAO, 2018). As a consequence, several drought early warning systems (EWS) have been developed to avert and minimise the impacts of these hazards.

Global initiatives, such as the 2015 Paris Agreement and the United Nation's Sustainable Development Goals (SDGs) recognise the importance of establishing robust EWS to save lives and livelihoods (UNFCCC, 2015). Existing EWS combine data on biophysical indicators that measure hazard risk with a series of socio-economic factors to account for vulnerability and exposure for early action. Satellite Earth Observation (EO) rainfall estimates and vegetation health are some of the datasets commonly used to monitor these drought conditions. The USAID's Famine Early Warning Systems Network (FEWS NET) utilises household livelihood information, rainfall estimates and the Normalized Difference Vegetation Index (NDVI) to monitor drought and its impact on food security (FEWSNET, 2019). In Kenya, the National Drought Management Authority (NDMA) monitors EO based biophysical indicators in combination with forage, livestock conditions and socio-economic data to monitor and anticipate future drought scenarios for early finance and early action (Klisch and Atzberger, 2016; FAO, 2017).

Recent research has highlighted robust methods for forecasting biophysical indicators used to measure vegetation condition. AghaKouchak (2014) harnessed the persistence property in soil moisture with the ensemble streamflow prediction (ESP) to provide skilful forecasts of the standardized soil moisture index for up to two months ahead. Barrett et al. (2020) forecasted the Vegetation Condition Index (VCI) with Auto-Regression (AR) and Gaussian Process (GP) models using historical values of the same indicator. Both models performed well for lead times up to 6 weeks. Adede et al. (2019) used a multivariate approach that considered the effects of exogenous variables on VCI. The model was based on an Artificial Neural Network (ANN) and provided precise forecasts for one month lead time. While these models showed good accuracies for short-range forecasts, forecasts with longer lead times beyond six weeks will provide disaster risk managers ample time to prepare and implement relief measures.

This paper aims to build on existing forecast initiatives and develop models that accurately forecast VCI at longer lead times. More specifically, our approach will include the interaction between the lagged information from indicators and variables like precipitation, soil moisture, and vegetation condition in an Auto-regressive distributed lag (ARDL) model (Gujarati, 2003; Pesaran and Shin, 1999). ARDL models are useful in situations where variable $Y_{t}$ at a time $t$ is influenced by other variables $X_{t}$ at time $t$ and the same variables at previous time steps $X_{t-i}$.

Parameter estimation with ARDL models has traditionally been carried out with a maximum likelihood approach which produces point estimates and often results in over-fitting leading to imprecise predictions (Martin, 2018). To address this, the ARDL model used in this work was implemented within a Bayesian framework which allows the incorporation of prior knowledge of the model parameters. This approach generates a posterior probability distribution for the model parameters which enables more accurate quantification of prediction uncertainties and allows for more robust risk analysis (Lambert, 2018). 
https://doi.org/10.5194/nhess-2021-223

Preprint. Discussion started: 16 August 2021

(c) Author(s) 2021. CC BY 4.0 License.

\subsection{Study Area}

This research was conducted in selected counties in the ASAL regions (see figure 2) of Kenya where the predominant activities are pastoralism and wildlife conservation. The farmers in these regions rely heavily on pastures and grasslands as the main source of feed for their animals (Sibanda et al., 2017). However, the erratic weather patterns in the eastern African region makes Kenya prone to frequent drought events (Gebremeskel et al., 2019). This poses a threat to food security and the countries economy as a whole. During the 2008-2011 droughts the Kenyan economy lost a total of 21.1 billion USD (Cabot Venton et al., 2012; Cenacchi, 2014). Hence the need to develop drought EWS with the ability to provide timely medium to long-range for drought preparedness.

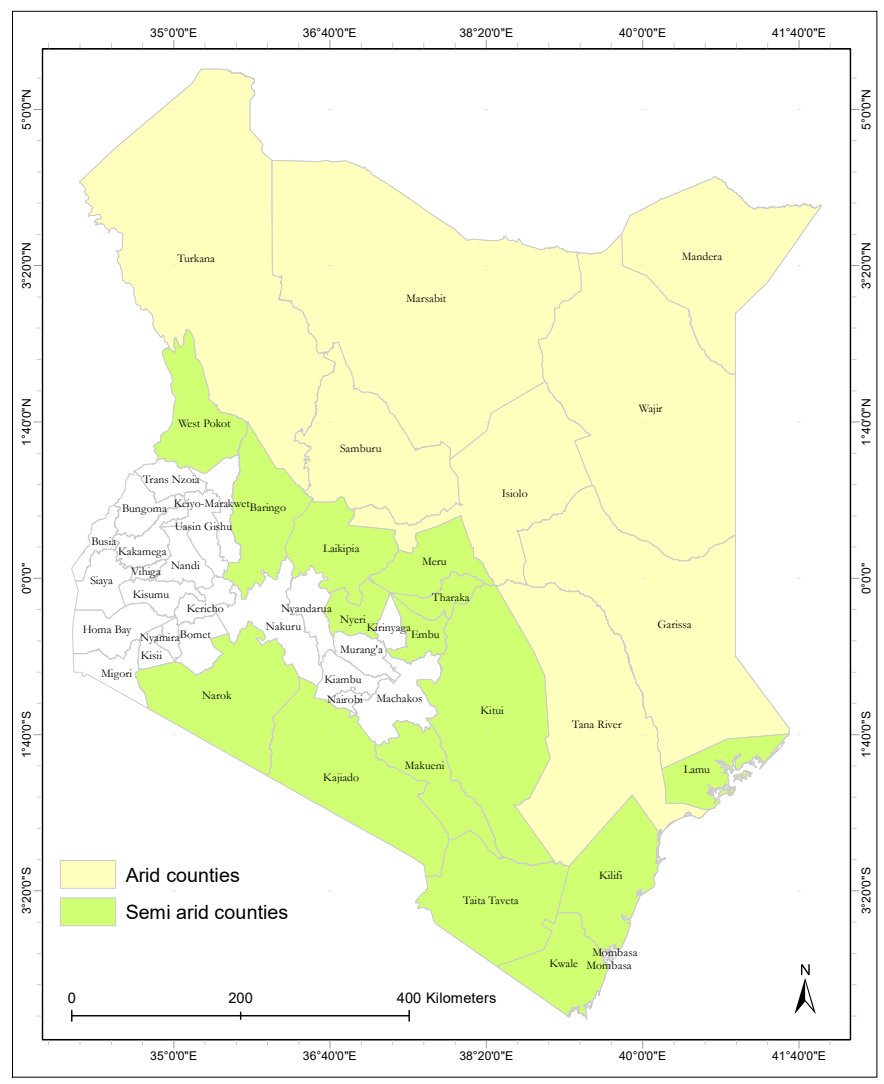

Figure 1. A map of Kenya showing the arid and semi-arid counties where the research was focused. 


\subsection{Data}

To enable our model to capture adequate historical information on drought and produce weekly forecasts we acquired daily data over a long period. Table 1 shows details of the satellite earth observation data used for this work.

Table 1. Summary of the datasets for the forecast model

\begin{tabular}{l|l|l|l|l|l} 
Data & Source (Producer) & $\begin{array}{l}\text { Spatial } \\
\text { Resolution }\end{array}$ & $\begin{array}{l}\text { Temporal } \\
\text { Resolution }\end{array}$ & $\begin{array}{l}\text { Acquisition } \\
\text { Period }\end{array}$ & $\begin{array}{l}\text { Unit of } \\
\text { Measure }\end{array}$ \\
\hline Precipitation & $\begin{array}{l}\text { Climate Hazards Group InfraRed } \\
\text { Precipitation (CHIRPS) } \\
\text { European Space Agency's } \\
\text { Climate Change Initiative (CCI) }\end{array}$ & $5 \mathrm{~km}$ & Daily & $2001-2018$ & $\mathrm{~mm}$ \\
Soil Moisture & $\begin{array}{l}\text { NASA MODIS (MCD43A4 v006) } \\
\text { Surface Reflectances }\end{array}$ & $500 \mathrm{~m}$ & Daily & $2001-2018$ & N/A
\end{tabular}

\subsubsection{Precipitation (Rainfall Estimates)}

The precipitation data were acquired from the Climate Hazards Group InfraRed Precipitation (CHIRPS) project (Funk et al., 2015). The CHIRPS data comprise a combination of weather station data and rainfall estimates captured via satellite remote sensing using the Cold Cloud Duration (CCD) (Milford and Dugdale, 1990) approach. The approach is used to estimates rainfall by using remote information on the period of time a cloud remains at a given temperature threshold. The final datasets are available as daily $5 \mathrm{~km}$ resolution images.

\subsubsection{Soil Moisture}

The daily 30km resolution soil moisture products by the European Space Agency's Climate Change Initiative (ESA-CCI) was used for this work. The data is produced from an algorithm that takes in back-scatter information from multiple active and passive Synthetic Aperture Radar (SAR) satellites. The values generated represent soil moisture at a soil depth of $10 \mathrm{~cm}$. The ESA-CCI Soil moisture products are available as passive, active or a combination of both. For this work, the combined version of the data is used (Gruber et al., 2019; Dorigo et al., 2017; Yang et al., 2017).

\subsubsection{Surface Reflectance}

80 The bidirectional reflectance distribution function (BRDF) corrected MODIS product, MCD43A4 Version 6, (Schaaf and Wang, 2015) was used to compute the NDVI and VCI. The product is available as daily 500m resolution images captured in 7 bands ranging from visible to infrared. Information on the vegetation health is derived from the Red and Near-Infra Red(NIR) bands via equation (1).

$\mathrm{NDVI}=\frac{N I R-R e d}{N I R+R e d}$ 


\subsection{Data pre-processing}

The datasets were acquired from January 1, 2001, to December 31, 2018, to correspond with the availability of soil moisture data at the time of research. Apart from the precipitation, clouded and low-quality pixels from poor atmospheric and radiometric correction were removed using the quality flags from the Quality Assurance (QA) maps that came with the surface reflectance and soil moisture products. Pixels representing grasslands and shrublands areas within our regions of interest were retrieved with the European Space Agency (ESA)'s 2016 Sentinel 2 Land Use and Land Cover (LULC) map. For the coastal semi-arid counties like Lamu and Kwale we could not extract enough soil moisture data so no results were shown for these counties.

To measure the drought condition at a period in time, the minimum and maximum NDVI values for a chosen baseline time interval and the NDVI value for that period are used to compute the Vegetation Condition Index (VCI) via equation (2) (Kogan, 1995). VCI values range from 0-100, with values below 35 depicting a moderate to severe drought condition (Klisch and Atzberger, 2016).

$\mathrm{VCI}_{i}=100 \times \frac{\mathrm{NDVI}_{i}-\mathrm{NDVI}_{\mathrm{m} i n, i}}{N D V I_{\max , i}-N D V I_{\min , i}}$,

where $\mathrm{N} D V I_{\min , i}$ and $\mathrm{N} D V I_{\max , i}$ are the long-term minimum and long-term maximum NDVI values of a pixel at $i^{t h}$ week of the year.

Temporal gaps created by the removal of poor quality pixels were filled with the Radial Basis Function (RBF) interpolation method (Rippa, 1999). This approach was used to avoid interpolated values for periods with longer gaps from going over the valid ranges. Noise resulting from faulty instruments were reduced with the Whittaker smoother (Eilers, 2003), which filters noise via a penalised least-squares. Since our target variable was computed from the long term minimum and maximum NDVI, the additional variables were also converted to anomalies by subtracting their long term means to produce soil moisture anomaly and precipitation anomaly. The persistence within individual variables was enhanced by computing with three months (12 weeks) rolling averages to derive three-month $\mathrm{VCI}(\mathrm{VCI} 3 \mathrm{M})$, three-month precipitation (P3M) and three-month soil moisture (SM3M). Finally, the precipitation and soil moisture data were standardised to eliminate any associated units of measurements and avoid the dominance of certain variables. This was done by subtracting their mean and dividing it by the standard deviation. 
https://doi.org/10.5194/nhess-2021-223

Preprint. Discussion started: 16 August 2021

(c) Author(s) 2021. CC BY 4.0 License.
Natural Hazards and Earth System Sciences

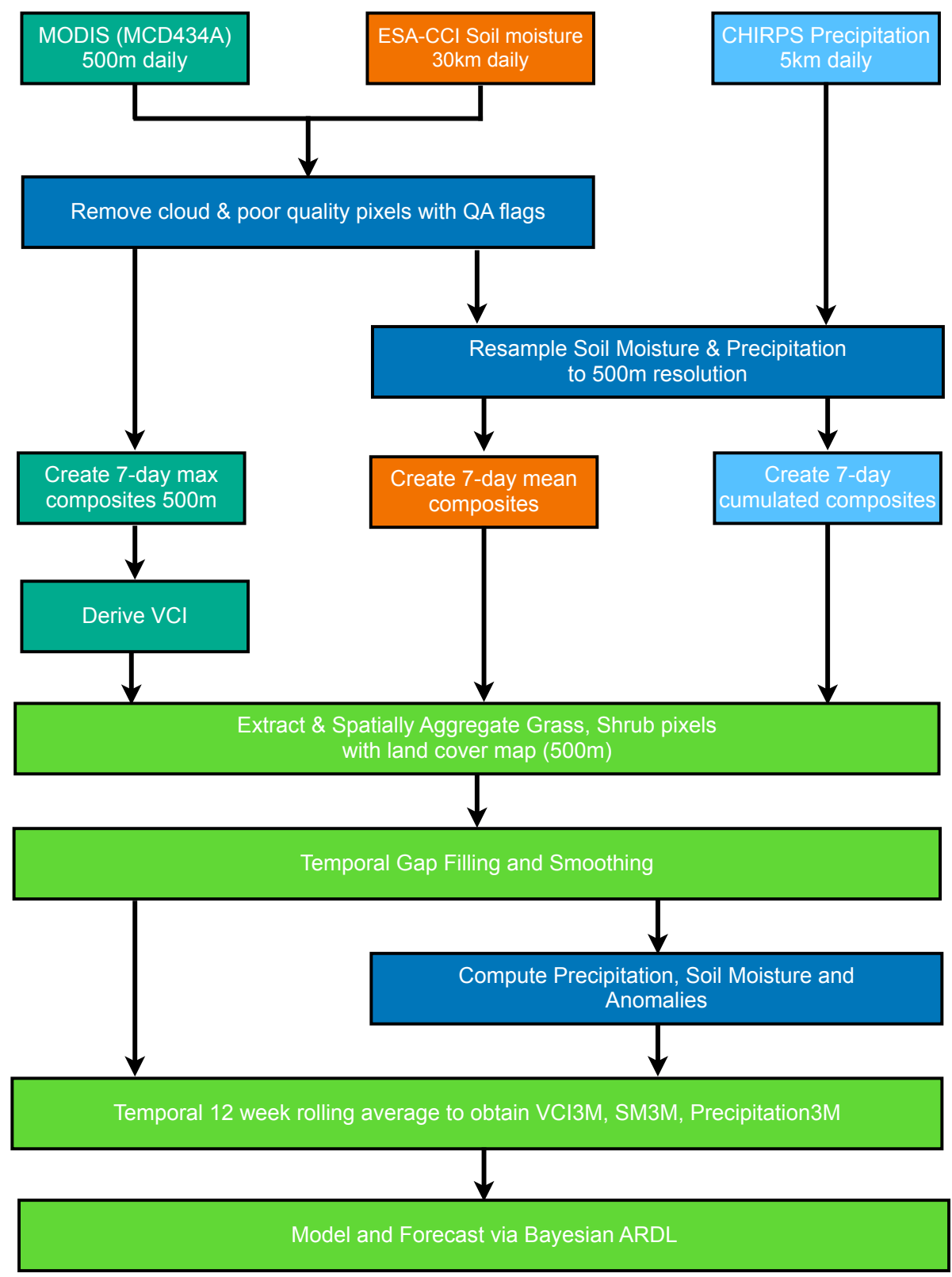

Figure 2. A flow chart showing data prepossessing and modelling

\subsection{Drought Model and Forecasting}

110 The Auto-Regressive Distributed Lag (ARDL) modelling approach used for this work is a generalised form of Auto Regression (AR) method mainly used for multivariate time series analysis. The method enables the variable of interest (dependent variable) 
to be modelled as a function of its lags and that of additional explanatory variables (independent variable) (Gujarati, 2003). An $\operatorname{ARDL}(p, q)$, consists of $p$, which represents the number of lags of the independent variable and $q$, which is the auto-regressive part of the model, represents the number of lags of the dependent variable. This approach has been extensively used in the field of economics and modelling the effect of climate and environmental variables on vegetation (Lei Ji and Peters, 2004; Ji and Peters, 2005).

For this study, however, parameter estimation for the ARDL was implemented within a Bayesian framework instead of using maximum likelihood methods based on Ordinary Least Squares (OLS). The Bayesian framework enables the incorporation of domain knowledge about the parameters through the use of informative priors. The model parameters, with this approach, are inferred using the Markov Chain Monte Carlo (MCMC) (Neal, 1993) sampling algorithm. The sampling process generates posterior probability distribution of the model parameters. As a consequence, we get a full probability distribution of forecast values for all lead time, which makes it easy to quantify forecast uncertainty for making informed decisions (Martin, 2018; Lambert, 2018).

The MCMC is a well-established sampling algorithm used for parameter inference in Bayesian models. However, Asaad and Magadia (2019), outlined some of its limitations and recommended the use of the Hamiltonian Monte Carlo (HMC) (Hoffman and Gelman, 2014), an improved variant of the traditional MCMC algorithm which is based on Hamiltonian dynamics and converges faster to a global minimum for models with high dimensional parameter space. (Robert et al., 2018). Parameter inference for this work was done with the No-U-Turn Sampler (NUTS)(Hoffman and Gelman, 2014) version of HMC implemented with PyMC3 (Salvatier et al., 2016) Python package.

The Bayesian ARDL model used for forecasting VCI3M with lagged P3M, and S3M is defined as:

$D_{t+n}=\alpha_{0}+\sum_{i=0}^{q} \beta_{d} D_{t-q}+\sum_{i=0}^{p} \theta_{p} P_{t-p}+\sum_{i=0}^{p} \delta_{s} S_{t-p}+\epsilon_{t-p}$

where $D_{t+n}$ is the drought index at $n$ lead time, $D_{t-q}$ are the lags ( 0 , to $q$ ) of drought indicator (Dependent variable). $P_{t-p}$, $S_{t-p}$ represent the lags 0 , to $p$, for precipitation, and soil moisture respectively. $\alpha_{0}$ is a constant representing the intercept and $\beta_{d}, \theta_{p}$, and $\delta_{s}$ are the regression coefficients of the input variables with $\epsilon_{t-p}$ being the error term which is assumed to be Gaussian.

Equation (3) can re-written as:

$D_{t+n}=\alpha+\sum_{i=0}^{i} \beta_{i} X_{t-i}+\epsilon_{t-i}$

where $n$ is the lead time, $\beta_{i}$ are the model parameters and $X_{t-i}$ represent the lagged input variables in equation 3.

The Bayesian approach makes explicit the prior beliefs about model parameters, which are then updated given some new data via the likelihood function, to give the posterior probability distribution. 
Parameter inference with the Bayesian framework is based on Bayes' theorem via the equation below:

$P\left(\theta \mid X_{t}\right)=\frac{P\left(X_{t} \mid \theta\right) \cdot P(\theta)}{P\left(X_{t}\right)}$

where $X_{t}$ represents $D_{t-q}, P_{t-p}, S_{t-p}, P\left(\theta \mid X_{t}\right)$ is the posterior or the probability of our model parameters given our data $X_{t}, P\left(X_{t} \mid \theta\right)$ is the likelihood or the probability of the data given the parameters, $P(\theta)$ is our prior belief about the parameters.

$P\left(X_{t}\right)$, known as the evidence, is a normalisation term that represents the probability of the data. The term is difficult compute and usually ignored (Lambert, 2018; McElreath, 2016). Thus the equation (5) for Bayes' theorem is re-written as:

$P\left(\theta \mid X_{t}\right) \propto P\left(X_{t} \mid \theta\right) . P(\theta)$

To put the ARDL model (equation 4) in the context of equation 6, the likelihood function $P\left(X_{t} \mid \theta\right)$ is written as:

$P\left(X_{t} \mid \alpha, \beta_{i}, \sigma\right) \sim N\left(\alpha+\sum_{i=0}^{i} \beta_{i} X_{t-i}, \sigma_{t-i}\right)$

Equation 6 is practically intractable due the complex integrals required (Lambert, 2018) thus, the need to use the HMC algorithm (Hoffman and Gelman, 2014) for sampling model parameters.

The prior for the model's regression coefficients are assumed to be Gaussian $P(\theta)=N(\mu, \sigma)$ with $\mu$ set to 0 to allow inferred parameters to have both positive and negative values and a weakly informative $\sigma$ of 0.5 as a regularization prior. This was done to avoid the approximation of unreasonable parameters and (Martin, 2018).

\subsection{Selecting optimal lags and forecasting}

A full grid search was done with various combinations of $p$ and $q$ values for dependent and independent values to select the optimal $p$ and $q$ for the BARDL model. The Akaike Information Criterion (AIC) (Akaike, 1998) equation (8) and the $R^{2}$ (Equation 9) metric were used as the score criteria to choose the optimal lags. AIC enables model selection by determining the model that best fits the data. The model with lowest AIC value is preferred. Whereas the $R^{2}$ score explains how much variation in the observed data could be explained by the model. Valid $R^{2}$ scores range between $0 \& 1$ where models with scores close to 1 are considered more accurate. The search was done on lag values ranging from 1 to 16 weeks. The optimal lag values varied for different counties. However, across all counties, low AIC and high $R^{2}$ scores were obtained when all input variables were set to a lag of 6 weeks. The AIC scores are derived as follows:

$\mathrm{AIC}=\log \frac{R S S}{n}+2 K$

where the $R S S$ is the residual sum of squares error, $n$ is the number of data points and $K$ is the number of estimated parameters.

The $R^{2}$ scores are derived as follows:

$R^{2}$-score $=1-\frac{\sum_{i}\left(y_{i}-f_{i}\right)^{2}}{\sum_{i}\left(y_{i}-\bar{y}\right)^{2}}$, 
where the $y_{i}$ are the observed data, and the $f_{i}$ are the forecasts.

Forecasting with the BARDL was done using the direct multi-step forecast approach, where separate models are fitted for $n$ step ahead forecasts (Ben Taieb et al., 2010; Ben Taieb and Hyndman, 2014). To fit the model for $n$ steps ahead, the data was restructured to offset values of the dependent $\left(D_{t+n}\right), n$ weeks from lag $0 X_{t-0}$ for all input variables. A rolling window cross-validation approach (Hyndman and Athanasopoulos, 2018) was used for model training and forecasting.

\subsection{Forecast skill assessment}

The performance of the models was assessed by measuring the accuracy, i.e. how well the forecasts agree with the observations and the precision, i.e. the quoted uncertainty and the accuracy of that uncertainty.

The model accuracy was evaluated with the $\mathrm{R}^{2}$ (equation 9) and Root Mean Squared Error (RMSE) (equation 10). The RMSE measures the mean deviation between the observed and forecast values.

$\mathrm{R} M S E=\sqrt{\frac{\sum_{i=1}^{n}\left(y_{i}-f_{i}\right)^{2}}{n}}$

where the $y_{i}$ are the observed data, $f_{i}$ are the forecasts and $n$ the total number of data points.

The precision, was quantified with the Prediction Interval Coverage Probability (PICP) and the Mean Prediction Interval Width (MPIW) (Pang et al., 2018) were also computed. The MPIW measures the average width between the upper $\left(u\left(D_{i}\right)\right)$ and lower bound $l\left(D_{i}\right)$ of a proportion of forecast distribution ( $n$ weeks ahead ) defined by a chosen prediction interval (e.g. $95 \%)$.

$\mathrm{MPI} W_{t+n}=\frac{1}{N} \sum_{i=1}^{m}\left|u\left(D_{i}\right)-l\left(D_{i}\right)\right|$.

The PICP shows the percentage of time the observed variable lies within the credible interval of the forecast distribution and is derived as follows:

$P I C P_{t+n}=\frac{1}{N} \sum_{i=1}^{m} c_{i}$

where $N$ is the number of predicted samples and $c_{i}$ is either 0 , or 1 . If the observed drought target variable falls within the upper and lower bound of the forecast distribution ( $n$ weeks ahead) then $c_{i}=1$; else $c_{i}=0$ if otherwise.

The goal is to minimize the MPIW while maintaining a high PICP value. A high PICP value (0.90 to 0.99) indicates that the observed values lie within the forecast distribution and a low MPIW value indicates a more precise forecast (Su et al., 2018). For the AR model, the confidence interval used to derive its PICP and MPIW was computed with the forecast RMSE and zscore of 1.96 representing the $95 \%$ confidence level of a standard normal distribution. This was done to permit its comparison to the output of the full BARDL model.

The contribution of the individual lagged inputs in the ARDL model were also measured by computing their percentage relative importance via the Relative Weight Analysis method (Tonidandel and LeBreton, 2011). With this approach, the inputs 
variables are initially transformed into orthogonal variables. Through an iterative process, each orthogonal variable is added to a linear regression model and the change in $\mathrm{R}^{2}$ score for each iteration is measured and expressed as a percentage of the total $\mathrm{R}^{2}$ score.

The Receiver operating characteristic (ROC) curve was also plotted to see how well the model forecasts a drought event given a threshold. The forecast distribution from our BARDL model enabled the computation of forecast probabilities given some drought thresholds. The model's ability to forecast these probabilities correctly was also assessed by plotting and analysing a Reliability Diagram and Sharpness. The Reliability Diagram shows how well forecast probabilities for a given drought event agreed with its corresponding observed event while the Sharpness shows the frequency of a forecasted drought event. (WWRP, 2009; Wilks, 2006).

\section{Results}

\subsection{Forecast accuracy}

AR modelling approach had proved to be skilful for short-range (2 to 6 weeks lead time) VCI3M forecasts (Barrett et al., 2020). However, the goal of this study was to extend the forecast range beyond 6 weeks while maintaining high accuracy by using the

210 BARDL model and considering the effect of exogenous factors like precipitation and soil moisture. The results shown in this section are for 6 to 12 weeks lead time for the BARDL models and with the AR modelling as a comparative baseline.

The contour plots in Figure 3, shows a joint distribution of the observed VCI3M and forecasted VCI3M at 6, 8, 10 \& 12 weeks for both AR and the BARDL models. For each plot, the correlation $(r)$, RMSE and $\mathrm{R}^{2}$ were computed. Overall, the results from the BARDL model showed a roughly 2-week gain in the performance metrics. For instance, $R^{2}$ score for the AR model at 6 weeks is equivalent to $R^{2}$ score at 8 weeks lead time for the BARDL models. This pattern can be seen across all forecast ranges for the RMSE as well. 

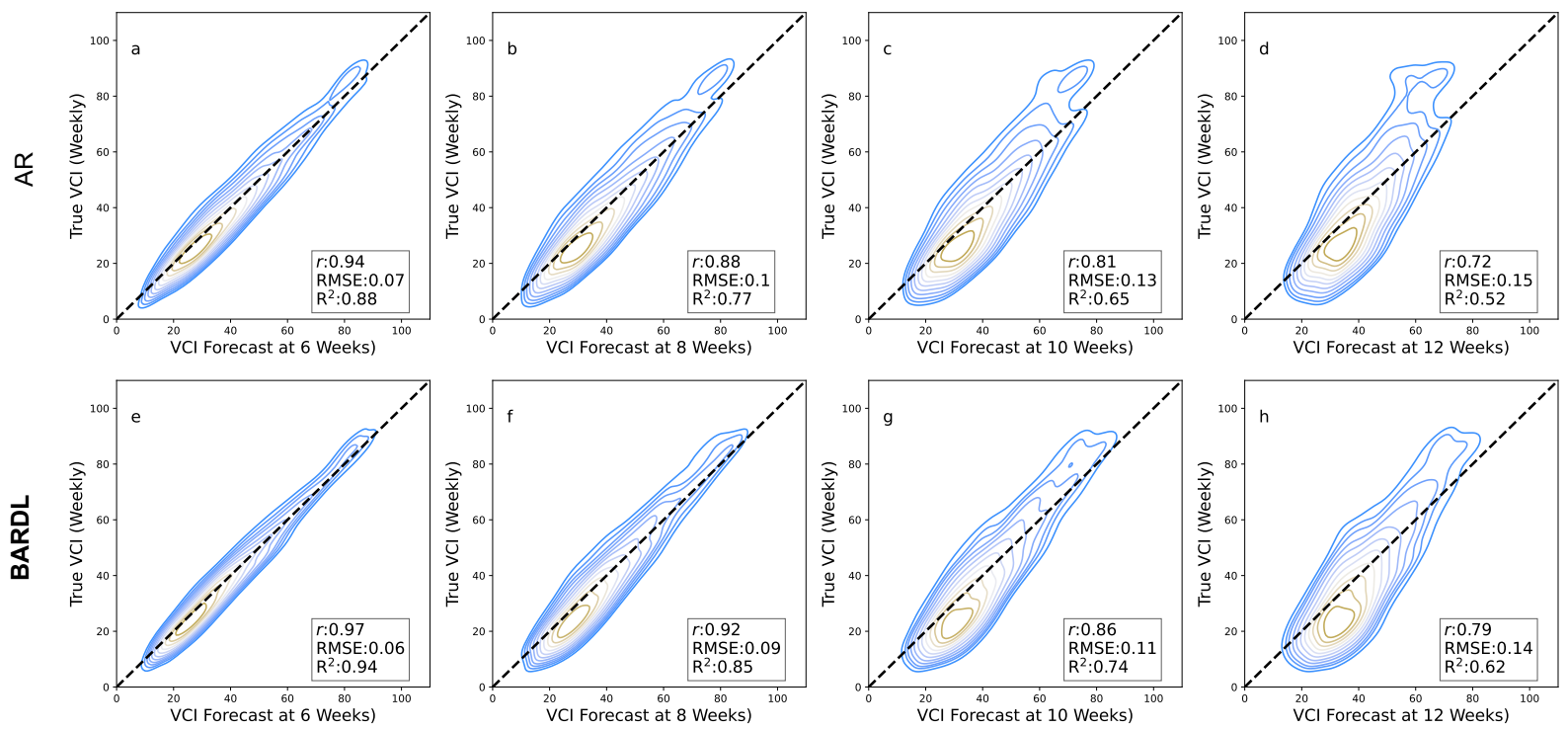

Figure 3. Contour plots showing VCI3M forecast against True VCI3M. Plots (a,b,c,d) shows the results from the AR method with VCI3M only, (e,f,g,h) shows the overall results for BARDL modelled with lags of VCI3M plus lags of Precipitation (P3M) and Soil Moisture (S3M) Anomalies for 6, 8, 10 and 12 weeks lead time for all counties

The performance metrics for the BARDL model in comparison to the AR model are shown in figure 4. This shows a significant improvement in performance at the same lead-time and, as a consequence, similar performance in the BARDL models is seen 2 weeks ahead of the AR models.
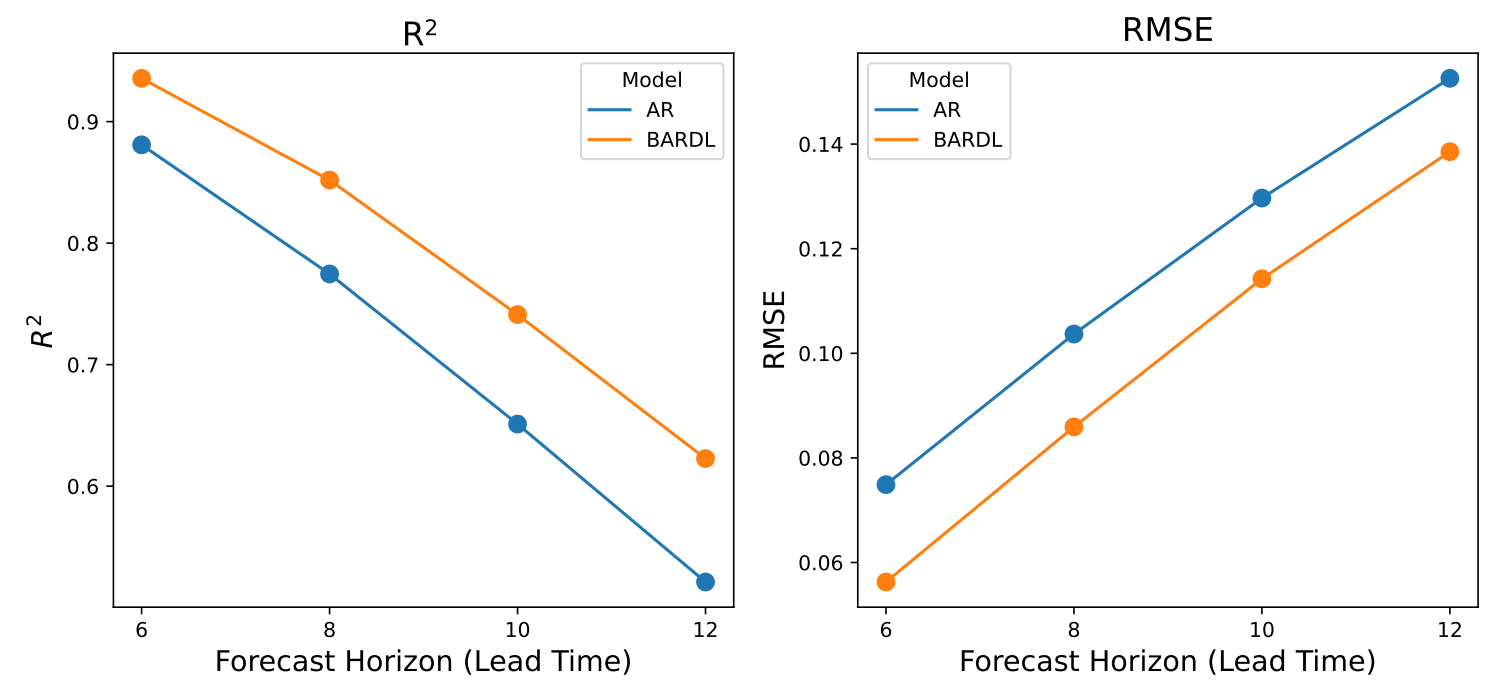

Figure 4. Performance metrics used to measure model accuracy as a function of forecast lead time. $R^{2}$ (Left), RMSE (Right). 
https://doi.org/10.5194/nhess-2021-223

Preprint. Discussion started: 16 August 2021

(c) Author(s) 2021. CC BY 4.0 License.

(c) (1)

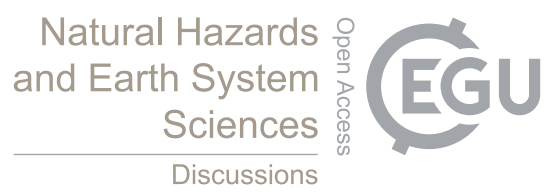

Table 2 shows the $\mathrm{R}^{2}$ scores for 6 to 12 weeks forecasts for AR and BARDL models at the county level for arid and semiarid regions. Just as observed in the contour plots, significant improvements are seen from 6 to 10 weeks lead time across all counties. In an arid county like Mandera, the $\mathrm{R}^{2}$ improved from 0.84, 0.72 and 0.58 using AR to $0.93,0.84$ and 0.73 using BARDL for 6, 8 and 10 weeks lead times respectively. Kitui in the semi-arid region also showed an improvement in $\mathrm{R}^{2}$ score from $0.84,0.71$ and 0.57 to $0.91,0.81$ and 0.67 for weeks 6,8 and 10 respectively. Overall the BARDL method demonstrated 225 better results compared to the AR across all counties. 
Table 2. $\mathrm{R}^{2}$ scores (6 to 12 weeks lead times) for AR modelled with lags of VCI3M only, BARDL modelled with lags of VCI3M with Precipitation (P3M) and Soil Moisture (SM3M) for arid and semi-arid counties.

\begin{tabular}{|c|c|c|c|c|c|c|c|c|c|}
\hline & \multirow[t]{2}{*}{ County } & \multicolumn{4}{|c|}{$\mathbf{A R}$} & \multicolumn{4}{|c|}{ BARDL } \\
\hline & & 6 & 8 & 10 & 12 & 6 & 8 & 10 & 12 \\
\hline \multirow{10}{*}{ 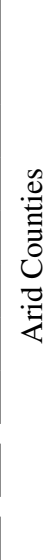 } & Garissa & 0.88 & 0.78 & 0.66 & 0.54 & 0.92 & 0.83 & 0.71 & 0.60 \\
\hline & Isiolo & 0.89 & 0.79 & 0.67 & 0.55 & 0.95 & 0.88 & 0.77 & 0.66 \\
\hline & Mandera & 0.86 & 0.74 & 0.60 & 0.46 & 0.93 & 0.84 & 0.73 & 0.63 \\
\hline & Marsabit & 0.91 & 0.81 & 0.69 & 0.54 & 0.96 & 0.90 & 0.80 & 0.68 \\
\hline & Samburu & 0.88 & 0.75 & 0.59 & 0.43 & 0.95 & 0.87 & 0.75 & 0.62 \\
\hline & Tana-River & 0.85 & 0.75 & 0.64 & 0.53 & 0.92 & 0.83 & 0.72 & 0.62 \\
\hline & Turkana & 0.90 & 0.79 & 0.65 & 0.50 & 0.96 & 0.89 & 0.79 & 0.65 \\
\hline & Wajir & 0.82 & 0.69 & 0.55 & 0.42 & 0.91 & 0.82 & 0.71 & 0.61 \\
\hline & Mean & 0.87 & 0.76 & 0.63 & 0.50 & 0.94 & 0.86 & 0.75 & 0.63 \\
\hline & Std. Dev. & 0.03 & 0.04 & 0.04 & 0.05 & 0.02 & 0.03 & 0.03 & 0.03 \\
\hline
\end{tabular}

\begin{tabular}{|c|c|c|c|c|c|c|c|c|c|}
\hline & & 6 & 8 & 10 & 12 & 6 & 8 & 10 & 12 \\
\hline \multirow{14}{*}{ 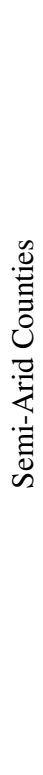 } & Baringo & 0.92 & 0.83 & 0.70 & 0.56 & 0.95 & 0.86 & 0.74 & 0.60 \\
\hline & Kajiado & 0.90 & 0.80 & 0.69 & 0.57 & 0.96 & 0.90 & 0.81 & 0.71 \\
\hline & Kilifi & 0.84 & 0.72 & 0.60 & 0.48 & 0.88 & 0.76 & 0.62 & 0.49 \\
\hline & Kitui & 0.84 & 0.70 & 0.56 & 0.43 & 0.92 & 0.81 & 0.68 & 0.53 \\
\hline & Laikipia & 0.93 & 0.85 & 0.73 & 0.59 & 0.97 & 0.91 & 0.81 & 0.67 \\
\hline & Makueni & 0.84 & 0.72 & 0.59 & 0.46 & 0.93 & 0.83 & 0.71 & 0.59 \\
\hline & Meru & 0.83 & 0.67 & 0.49 & 0.33 & 0.92 & 0.81 & 0.67 & 0.52 \\
\hline & Narok & 0.85 & 0.74 & 0.60 & 0.45 & 0.92 & 0.81 & 0.67 & 0.50 \\
\hline & Nyeri & 0.90 & 0.81 & 0.68 & 0.54 & 0.93 & 0.85 & 0.73 & 0.60 \\
\hline & Taita-Taveta & 0.86 & 0.74 & 0.60 & 0.47 & 0.92 & 0.81 & 0.69 & 0.59 \\
\hline & Tharaka-Nithi & 0.81 & 0.64 & 0.45 & 0.28 & 0.83 & 0.63 & 0.39 & 0.17 \\
\hline & West-Pokot & 0.91 & 0.82 & 0.69 & 0.54 & 0.95 & 0.86 & 0.72 & 0.57 \\
\hline & Mean & 0.87 & 0.75 & 0.62 & 0.48 & 0.92 & 0.82 & 0.69 & 0.54 \\
\hline & Std. Dev. & 0.04 & 0.06 & 0.08 & 0.09 & 0.04 & 0.07 & 0.10 & 0.13 \\
\hline
\end{tabular}

\subsection{Uncertainty Analysis (PICP and MPIW)}

The PICP and MPIW for a 95\% forecast confidence interval were computed for each lead time for both the AR and BARDL models. In figure 5, the time series plots show that the observed VCI3M values lie within the $95 \%$ forecast interval between 
https://doi.org/10.5194/nhess-2021-223

Preprint. Discussion started: 16 August 2021

(c) Author(s) 2021. CC BY 4.0 License.

(c) (i)

94-96\% of the time across all lead times for both the BARDL and AR models, indicating that the errors bounds are very good

for both. However, lower values of MPIW demonstrate that BARDL provided a more precise forecast. Appendix A, tabulates PICP and MPIW for 6 to 12 weeks forecasts for the AR and BARDL models for all counties (Table A1).
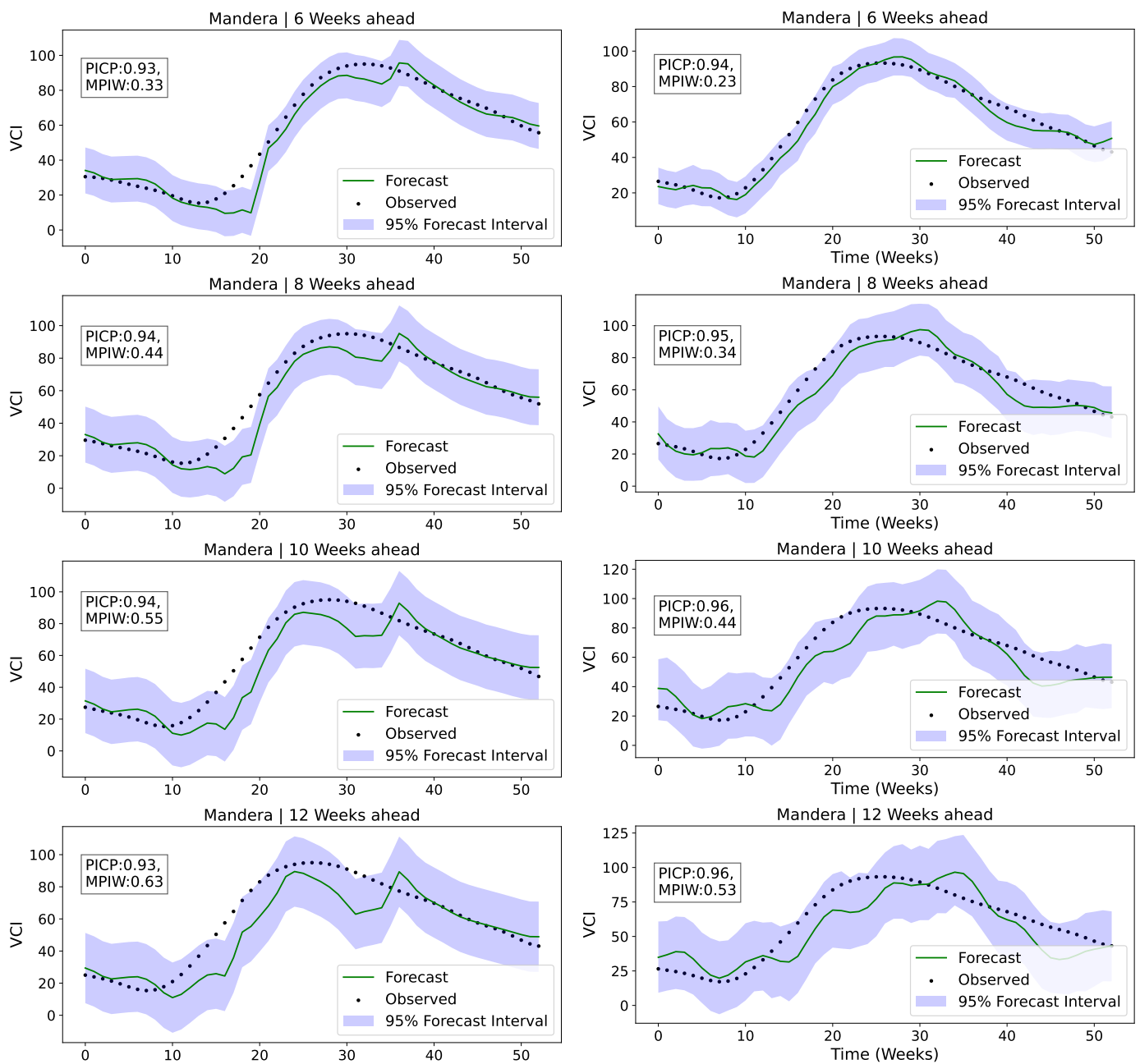

Figure 5. Time series plot showing uncertainty for 6, 8, 10, 12 weeks lead time for Mandera county. Plots on the left side are from the AR model and plots to the right are BARDL. The PICP and MPIW for the other counties can found in Appendix A

\subsection{Drought Events ROC Curve}

The Receiver Operating Characteristic (ROC) curve (figure 6) illustrates how well the model can discriminate drought events. Drought events are forecasted when the predicted VCI3M drops below a threshold and are deemed correct if the observed VCI3M is below 35 (moderate to severe drought) (Klisch and Atzberger, 2016). The ROC show the probability of a forecasted event being true (True Positive Rate (TPR)) against the chance of that predicted event being false alarm (False Positive Rate 
https://doi.org/10.5194/nhess-2021-223

Preprint. Discussion started: 16 August 2021

(c) Author(s) 2021. CC BY 4.0 License.

(FPR) as the threshold is varied. The Area Under the Curve (AUC), quantifies the ability of the forecast model to distinguish between drought events (Wilks, 2006; Bradley, 1997). The ROC curve and AUC metric for the BARDL model also demonstrated an improvement over the AR model. The points plotted on the curve represent the TPR and FPR where VCI3M $<35$. This indicates that when the AR model (Dotted curve), forecasts a drought condition (i.e VCI3M<35) for 6 weeks ahead, the probability of it being true is $86 \%$ with a FPR of $9 \%$. Whereas a forecast by the BARDL model (Solid curve) at the same 6 weeks had a TRP of $89 \%$ and a FPR of 7\%. The improvements with the BARDL model were mainly seen in the TPRs (6 to 10 week lead time) for the BARDL model while the FPR remained almost the same.

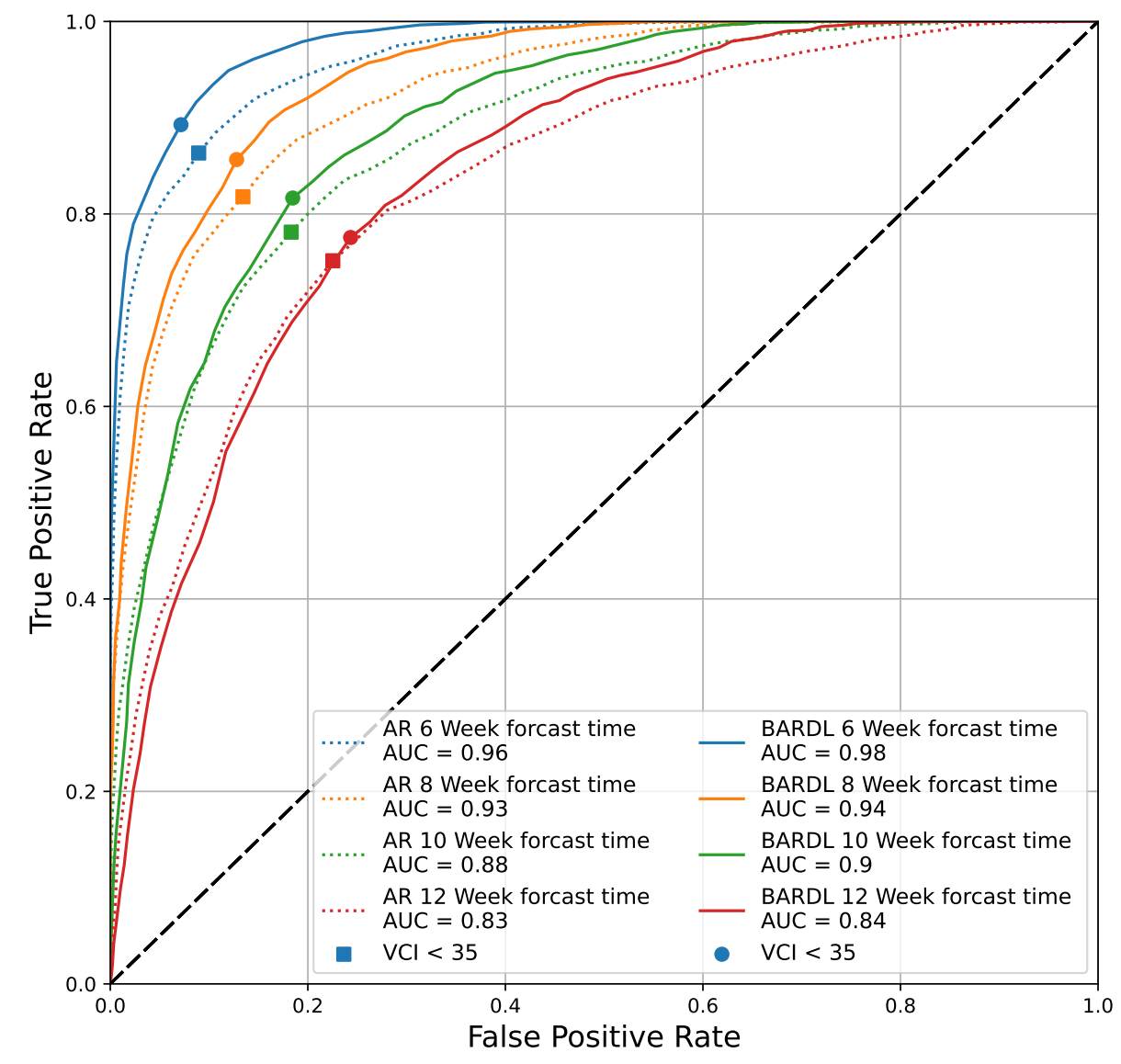

Figure 6. ROC Curve showing True Positive Rate (TPR), False Positive Rates(FPR) and AUC for 6,8,10,12 weeks for both AR (Dotted line) and BARDL (Solid line) forecasts. The VCI3M $<35$ threshold is plotted as points on the lines.

\subsection{Forecast Reliability}

Using the Bayesian approach also enabled the computation of forecast probabilities for a given drought event (No Drought Condition - VCI3m $>35$ or Drought Condition - VCI3M $<35$ ). To assess the skill for forecasting drought probabilities, we used the reliability diagrams in figure 7 . The plot shows a joint distribution between the forecast probabilities in bins and the 
frequencies of the observed drought events that fall in those bins. For each lead time, the sharpness histogram which shows the frequency at which an event is forecasted are also plotted (WWRP, 2009). The reliability of a perfect model would follow the line $y=x$ which has been represented by a dashed line in figure 7 . The closer a model is to this dashed line, the more reliable it is. Figure 7 shows the reliability for drought events $(\mathrm{VCI} 3 \mathrm{M}<35)$ in arid counties, the forecast skill assessment of our BARDL model indicates that when we forecast a 'Drought' condition with a probability between $80 \%$ to $100 \%$ for 6 week lead time, it corresponds with the observed drought events about $88 \%$ to $99 \%$ of the time. In terms of the model's sharpness, it can be seen that most of the drought events forecasted by the BARDL model have a probability between $90 \%$ to $100 \%$. The peak at the $0 \%$ to $10 \%$ bin of the sharpness plot shows the frequency of 'No Drought' forecasts in the arid counties. This indicates the likelihood of the model missing some drought events especially from 8 weeks lead time and beyond.
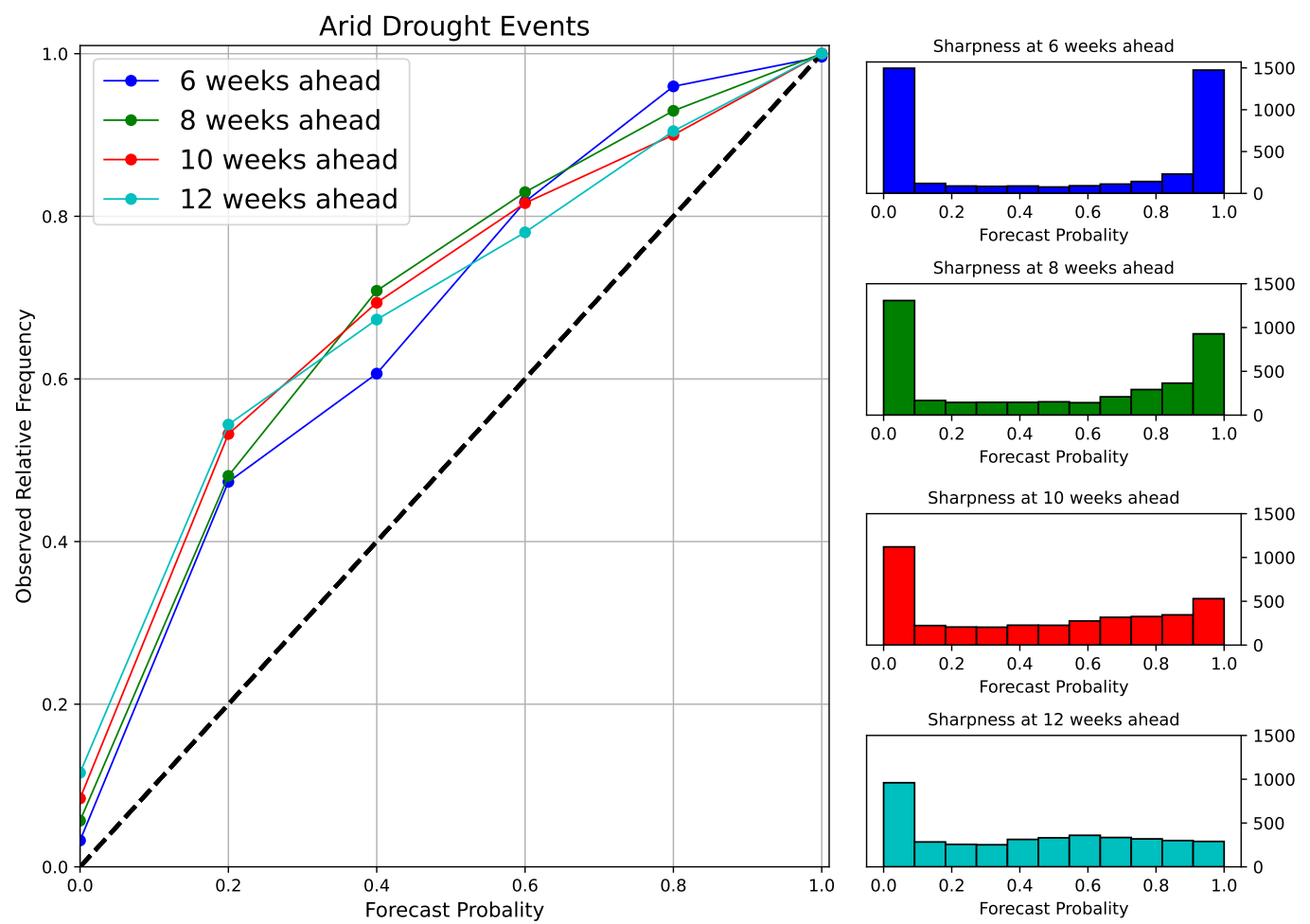

Figure 7. Reliability diagram showing forecast probability and their corresponding observed frequencies for 6, 8, 10, 12 weeks lead time together with their corresponding sharpness plots for drought events $(\mathrm{VCI} 3 \mathrm{M}<35)$ in the arid and semi-arid counties

\subsection{Relative Importance}

Figure 8 shows the cumulative percentage relative importance for the lags of VCI3M, P3M anomaly and SM3M anomaly. The lags of VCI3M contributes the most for shorter lead time and decreases longer lead times. The precipitation anomaly also contributes significantly to future VCI3M and its relative importance increases with increasing forecast lead times. The relative importance of soil moisture, although it varies less across various lead times, also contributes significantly. Detailed plots of 
the relative importance for individual lag contribution for each arid and semi-arid county in figure B1 (Appendix B). A critical look at these plots also showed that VCI3M responds better to precipitation anomaly in most arid counties like Turkana and Wajir compared to semi-arid counties like Kitui and West-Pokot.

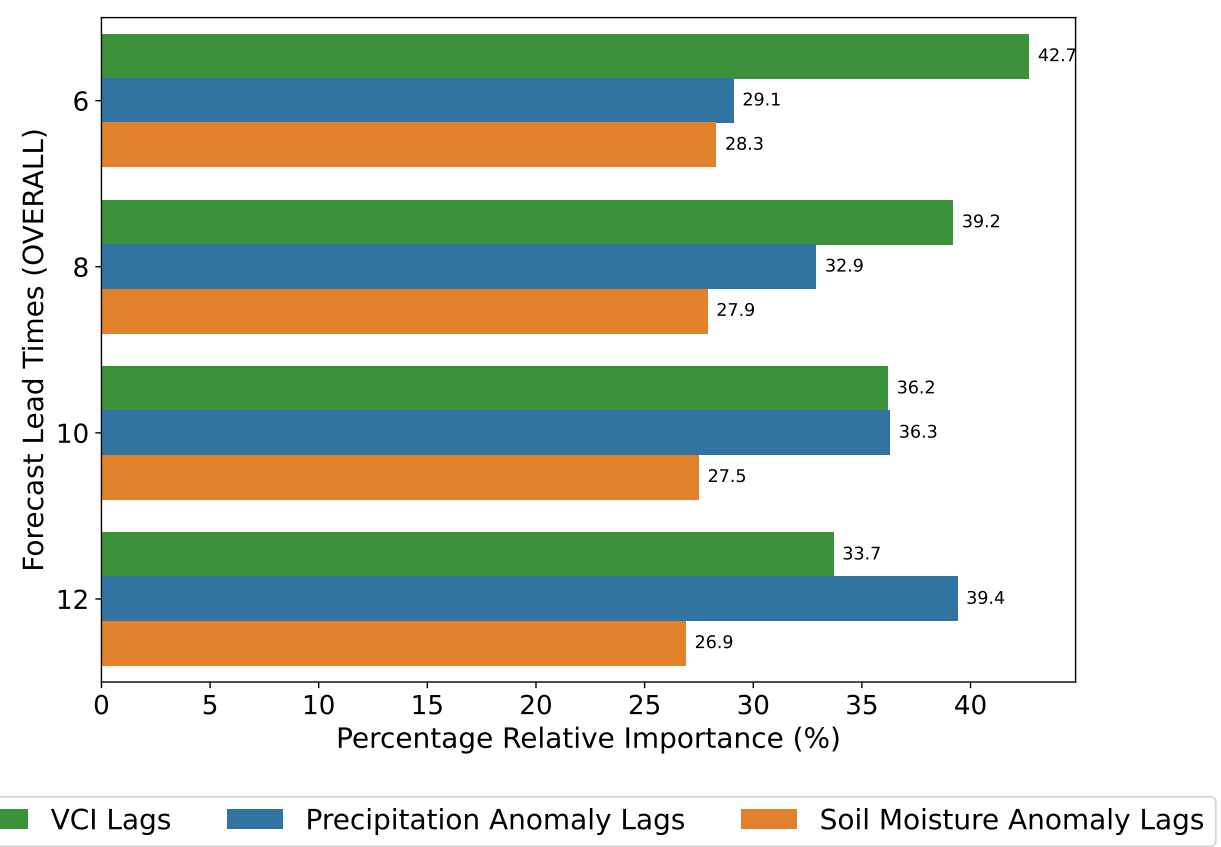

Figure 8. Bar plots showing the cumulative (All lags) relative importance of additional variables to the VCI3M forecast for all counties

\section{Discussion}

In this paper we increased the range of VCI3M forecasts, using additional lagged information from P3M and S3M anomalies. The VCI3M used here was derived from the 12-week rolling mean of VCI, as used by Kenya's National Drought Management Authority (NDMA) for monitoring and reporting agricultural droughts occurrences. The soil moisture data especially, though retrieved via a combination of remote sensing and a soil moisture model (Gruber et al., 2019), has proved useful for drought monitoring and forecast. The extensive model skill assessments done here shows that our Bayesian ARDL approach not only performs better compared to results from previous studies (Barrett et al., 2020) but also, the BARDL model, by design, provides additional uncertainty information for better decision making.

Our BARDL which incorporates the precipitation and soil moisture exhibited a 2-week gain in forecast range with overall $R^{2}$ scores of $0.94,0.85$ and 0.74 at 6,8 and 10 weeks lead time respectively. Our forecasts were mostly driven by the variables at lag 0 . However, the collective contribution of the additional lags substantially improved the forecast ranges. Finally, the skill assessment based on forecast probabilities indicated a good separation between No-Drought and Drought events. 
The results from the model evaluation revealed a strong persistence within soil moisture and VCI3M, a property that enables future values to be inferred from their past values (AghaKouchak, 2014). Despite this inherent persistence in the VCI3M, it still required the information from additional biophysical factors to improve its forecast range as seen in figure B1 and the overall performance of the BARDL model. Another interesting observation from figure ?? also showed that VCI3M responded very slowly to short term moisture anomalies (Quiring and Ganesh, 2010; Vicente-Serrano, 2007). From a spatial perspective, both models (AR \& BARDL) gave a higher forecast $R^{2}$ score in the arid areas compared to the semi-arid areas. This was more significant for the BARDL model.

Further evaluation of forecasts based on Kenya's long rain (March, April, May (MAM)) and short rain (October, November, December (OND)) seasons (Camberlin and Wairoto, 1997) also showed even better $R^{2}$ score for longer range forecast in MAM season compared to the OND for the BARDL model (see figures D1 and E1). This indicates that although VCI3M responds slowly to short term moisture levels, the impact of precipitation and soil moisture on vegetation condition is very important. The $R^{2}$ scores for the AR model in the MAM season however dropped significantly compared to the OND season. A possible reason for this observation, especially during the MAM season, could be attributed to the absence of information from the moisture levels (precipitation and soil moisture) in the AR model. The relative importance (figure $\mathrm{C} 1$ ) of the lagged exogenous factors for different seasons also confirms the reliance of future VCI3M on precipitation anomalies. The contribution of the lagged soil moisture anomalies during the OND seasons also increased compared to the MAM season. This also indicates that during the short rain season, vegetation condition is also controlled by soil moisture. When it comes to forecasting drought events, a much higher frequency is seen during the OND season (see figure F1. This is expected since there are fewer rains in the OND seasons.

Aside from the significant improvements in the forecast range and precision, the strength of our model hinges on the fact that we implemented it in a Bayesian context. Using the Bayesian approach generates a full posterior probability distribution of forecasted VCI3M values which gave us the power to easily gain insight into the uncertainty of forecasted VCI3M values (Lambert, 2018). It also allowed the computation of probabilistic forecast of specific drought events (e.g. VCI3M falling in a particular range) (Wilks, 2006). For our target end-users and stakeholders like the NDMA, using the Bayesian model proposed in this paper as part of their EWS will enable them to confidently report on drought events. Also, policymakers and administrators of disaster relief organisations based on the forecast-based finance initiatives (Coughlan de Perez et al., 2015), can make better decisions and prioritise which drought alarms to act on. This will help with the efficient management of funds.

Although we have shown that we can extend forecast ranges with the added variables, a key limitation to moving this forward is the availability of soil moisture data. The ESA CCI Soil Moisture products used in this paper are released annually and are also a year behind. Thus they cannot currently be used for producing real-time forecasts.

\section{Conclusion and Future Work}

In this study we have made two key developments, these include primarily, the improvement in the forecast range of VCI3M using lagged information from precipitation ( $\mathrm{P} 3 \mathrm{M})$ and soil moisture (S3M) by approximately 2 weeks compared to previous 
https://doi.org/10.5194/nhess-2021-223

Preprint. Discussion started: 16 August 2021

(c) Author(s) 2021. CC BY 4.0 License.

(c) (1)

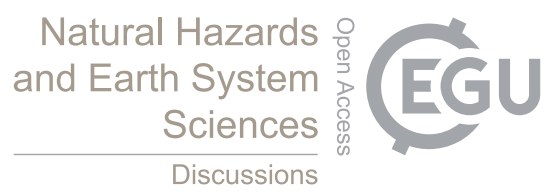

310 works. Secondly, modelling within the Bayesian framework also gave the added advantage of easily assessing model uncertainty and forecast probability of a drought event.

The forecast-based finance initiatives aimed at monitoring agricultural drought indicators and their impact on livelihoods should consider Bayesian approaches to enable better decision making. We would also recommend that soil moisture data be made available sooner and promptly to enable near real-time forecasting of vegetation condition via our proposed method.

315 The disparity in model performance between arid and semi-arid regions points to the fact that the differences in climate and vegetation land use and land cover (LULC) should also be considered when developing such forecast models. A natural expansion of our BARDL model would be to simultaneously explore and model for spatial variations like LULC in a county or any region of interest via a hierarchical modelling approach. Doing this will give us the advantage of pooling information between spatial variations, whilst still allowing flexibility between them. 
https://doi.org/10.5194/nhess-2021-223

Preprint. Discussion started: 16 August 2021

(C) Author(s) 2021. CC BY 4.0 License.

Code and data availability. Link to Data and Code repository https://github.com/edd3x/Bayesian-ARDL.git

Appendix A: A table showing the PICP and MPIW (in brackets) estimates for the arid and semi-arid counties

Table A1. The PICP and MPIW (in parenthesis ) estimates for the all arid and semi-arid counties.

\begin{tabular}{|c|c|c|c|c|c|c|c|c|c|}
\hline & \multirow[t]{2}{*}{ County } & \multicolumn{4}{|c|}{ AR Model } & \multicolumn{4}{|c|}{ BARDL Model } \\
\hline & & 6 & 8 & 10 & 12 & 6 & 8 & 10 & 12 \\
\hline \multirow{9}{*}{ 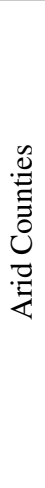 } & Garissa & $0.93(0.33)$ & $0.94(0.46)$ & $0.94(0.57)$ & $0.93(0.67)$ & $0.86(0.21)$ & $0.84(0.31)$ & $0.83(0.39)$ & $0.81(0.46)$ \\
\hline & Isiolo & $0.93(0.29)$ & $0.93(0.4)$ & $0.93(0.51)$ & $0.93(0.6)$ & $0.94(0.18)$ & $0.92(0.27)$ & $0.9(0.36)$ & $0.89(0.43)$ \\
\hline & Mandera & $0.93(0.33)$ & $0.94(0.44)$ & $0.94(0.55)$ & $0.93(0.63)$ & $0.94(0.23)$ & $0.95(0.34)$ & $0.96(0.44)$ & $0.96(0.53)$ \\
\hline & Marsabit & $0.92(0.25)$ & $0.91(0.36)$ & $0.93(0.46)$ & $0.94(0.56)$ & $0.93(0.15)$ & $0.9(0.23)$ & $0.88(0.32)$ & $0.88(0.38)$ \\
\hline & Samburu & $0.95(0.26)$ & $0.94(0.37)$ & $0.95(0.47)$ & $0.95(0.56)$ & $0.95(0.17)$ & $0.97(0.27)$ & $0.95(0.37)$ & $0.94(0.44)$ \\
\hline & Tana-River & $0.94(0.32)$ & $0.93(0.43)$ & $0.94(0.51)$ & $0.94(0.58)$ & $0.87(0.2)$ & $0.86(0.28)$ & $0.85(0.35)$ & $0.85(0.41)$ \\
\hline & Turkana & $0.95(0.24)$ & $0.95(0.34)$ & $0.95(0.43)$ & $0.95(0.52)$ & $0.92(0.14)$ & $0.92(0.23)$ & $0.93(0.33)$ & $0.94(0.41)$ \\
\hline & Wajir & $0.94(0.37)$ & $0.94(0.49)$ & $0.94(0.59)$ & $0.95(0.67)$ & $0.9(0.22)$ & $0.89(0.32)$ & $0.9(0.4)$ & $0.9(0.48)$ \\
\hline & Mean & $0.94(0.3)$ & $0.94(0.41)$ & $0.94(0.51)$ & $0.94(0.6)$ & $0.91(0.19)$ & $0.91(0.28)$ & $0.9(0.37)$ & $0.9(0.44)$ \\
\hline
\end{tabular}

\begin{tabular}{|c|c|c|c|c|c|c|c|c|c|}
\hline & & 6 & 8 & 10 & 12 & 6 & 8 & 10 & 12 \\
\hline \multirow{13}{*}{ 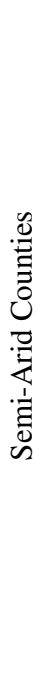 } & Baringo & $0.95(0.29)$ & $0.96(0.42)$ & $0.95(0.54)$ & $0.95(0.65)$ & $0.95(0.22)$ & $0.94(0.36)$ & $0.94(0.49)$ & $0.95(0.61)$ \\
\hline & Kajiado & $0.93(0.3)$ & $0.93(0.42)$ & $0.93(0.53)$ & $0.93(0.63)$ & $0.94(0.18)$ & $0.93(0.29)$ & $0.94(0.4)$ & $0.93(0.48)$ \\
\hline & Kilifi & $0.94(0.23)$ & $0.94(0.31)$ & $0.95(0.36)$ & $0.94(0.41)$ & $0.88(0.2)$ & $0.89(0.28)$ & $0.89(0.36)$ & $0.9(0.42)$ \\
\hline & Kitui & $0.93(0.34)$ & $0.95(0.47)$ & $0.94(0.57)$ & $0.94(0.64)$ & $0.9(0.21)$ & $0.89(0.31)$ & $0.88(0.4)$ & $0.89(0.47)$ \\
\hline & Laikipia & $0.94(0.24)$ & $0.95(0.35)$ & $0.96(0.46)$ & $0.96(0.56)$ & $0.96(0.17)$ & $0.95(0.28)$ & $0.94(0.4)$ & $0.93(0.5)$ \\
\hline & Makueni & $0.94(0.34)$ & $0.94(0.46)$ & $0.93(0.56)$ & $0.94(0.64)$ & $0.93(0.22)$ & $0.91(0.32)$ & $0.88(0.4)$ & $0.89(0.47)$ \\
\hline & Meru & $0.95(0.3)$ & $0.95(0.43)$ & $0.95(0.54)$ & $0.95(0.62)$ & $0.93(0.2)$ & $0.93(0.31)$ & $0.92(0.4)$ & $0.91(0.47)$ \\
\hline & Narok & $0.95(0.27)$ & $0.95(0.37)$ & $0.94(0.45)$ & $0.94(0.53)$ & $0.95(0.19)$ & $0.95(0.29)$ & $0.93(0.39)$ & $0.92(0.48)$ \\
\hline & Nyeri & $0.94(0.23)$ & $0.95(0.32)$ & $0.96(0.41)$ & $0.95(0.49)$ & $0.91(0.18)$ & $0.89(0.27)$ & $0.88(0.35)$ & $0.89(0.43)$ \\
\hline & Taita-Taveta & $0.92(0.32)$ & $0.92(0.44)$ & $0.92(0.55)$ & $0.93(0.63)$ & $0.85(0.2)$ & $0.84(0.29)$ & $0.84(0.38)$ & $0.85(0.44)$ \\
\hline & Tharaka-Nithi & $0.94(0.26)$ & $0.94(0.37)$ & $0.95(0.45)$ & $0.94(0.52)$ & $0.92(0.21)$ & $0.91(0.3)$ & $0.9(0.38)$ & $0.9(0.45)$ \\
\hline & West-Pokot & $0.96(0.25)$ & $0.96(0.36)$ & $0.95(0.47)$ & $0.95(0.56)$ & $0.95(0.19)$ & $0.94(0.32)$ & $0.93(0.44)$ & $0.95(0.54)$ \\
\hline & Mean & $0.94(0.28)$ & $0.94(0.39)$ & $0.94(0.49)$ & $0.94(0.57)$ & $0.92(0.2)$ & $0.91(0.3)$ & $0.91(0.4)$ & $0.91(0.48)$ \\
\hline
\end{tabular}


https://doi.org/10.5194/nhess-2021-223

Natural Hazards

Preprint. Discussion started: 16 August 2021

(c) Author(s) 2021. CC BY 4.0 License.

(c) (i)

\section{Appendix B: Relative Importance plots for each county}
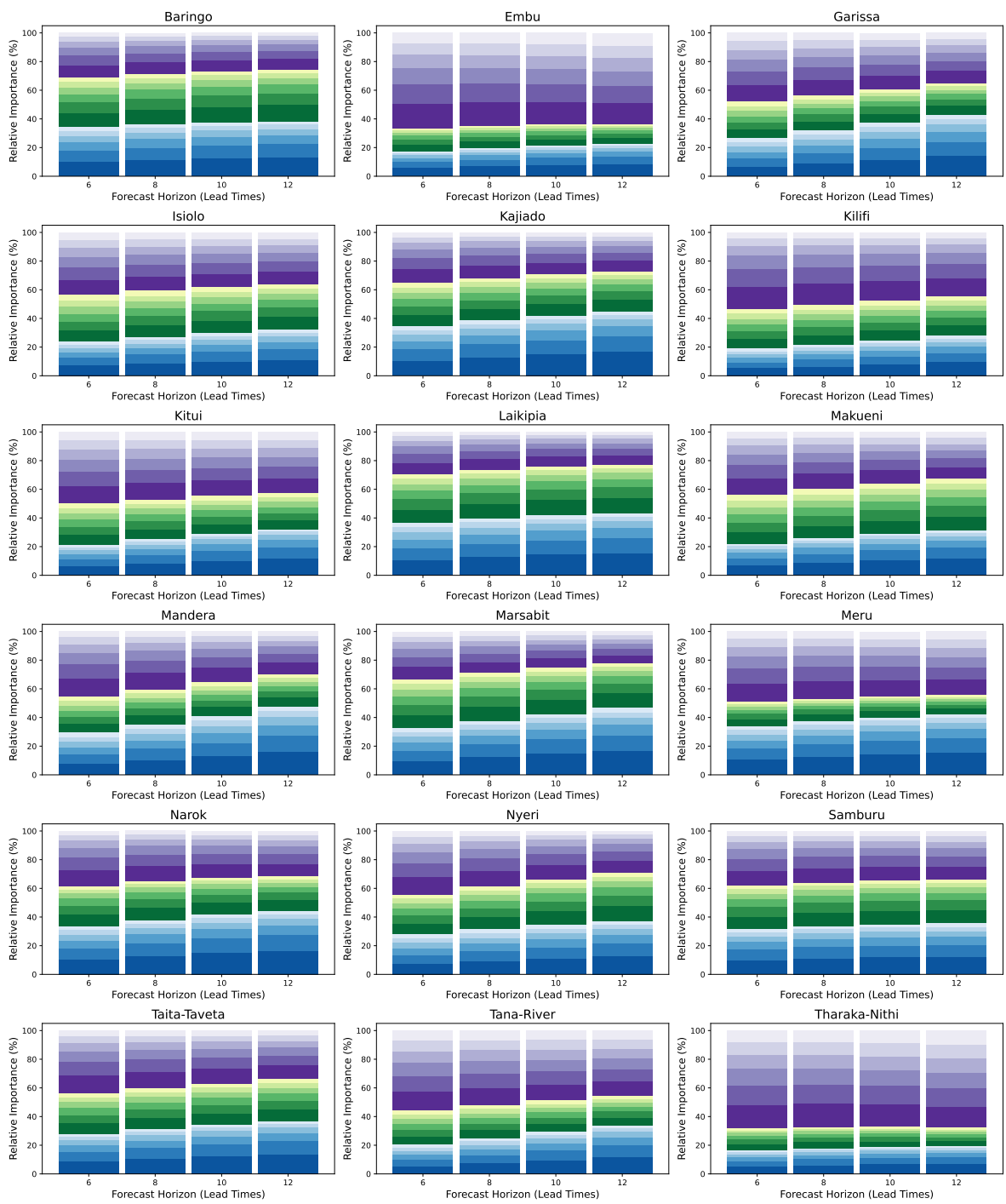

Tana-River

Tharaka-Nithi
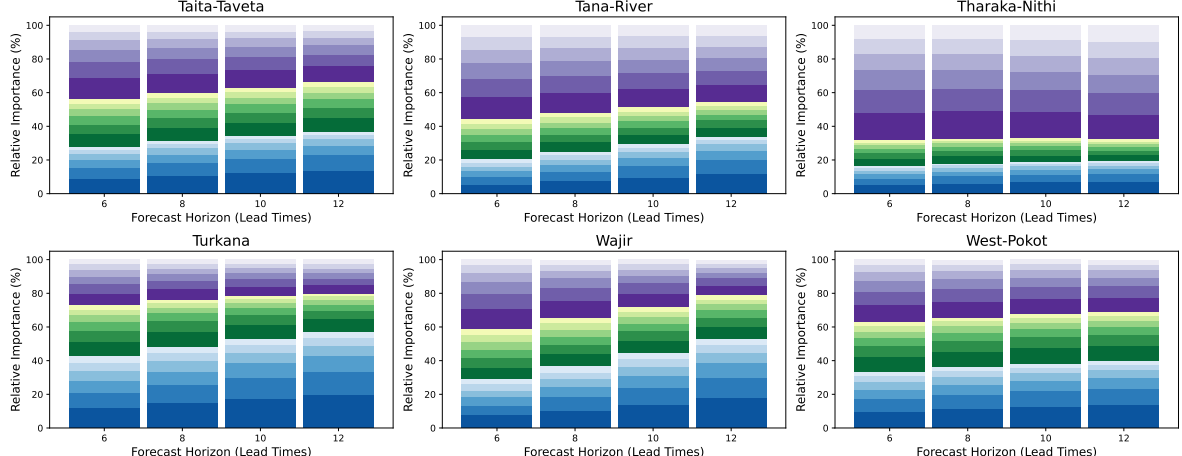

West-Pokot
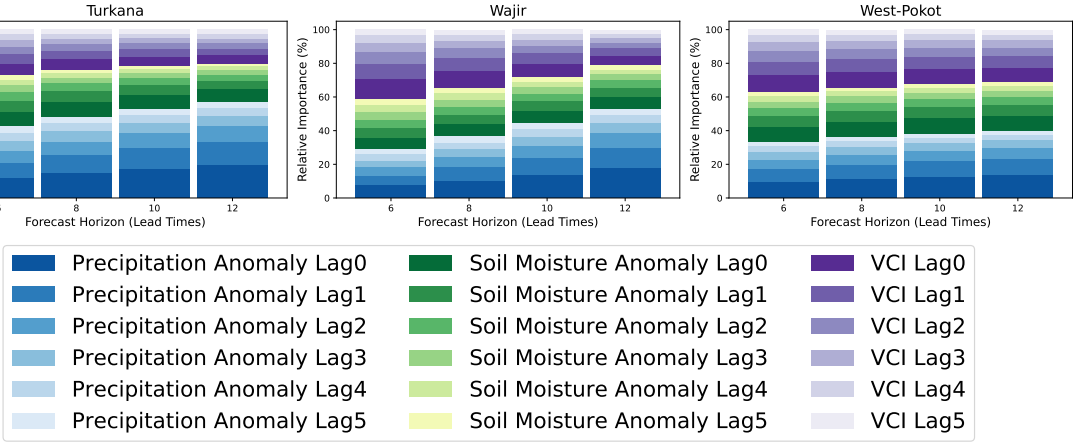

- Soil Moisture Anomaly Lag0 Soil Moisture Anomaly Lag1 Soil Moisture Anomaly Lag2

- Soil Moisture Anomaly Lag3

- Soil Moisture Anomaly Lag4 Soil Moisture Anomaly Lag5

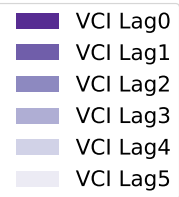

Figure B1. Relative Importance for each exogenous factors for each lag (0-5) variable per county. 


\section{Appendix C: Relative Importance plots for MAM and OND seasons}
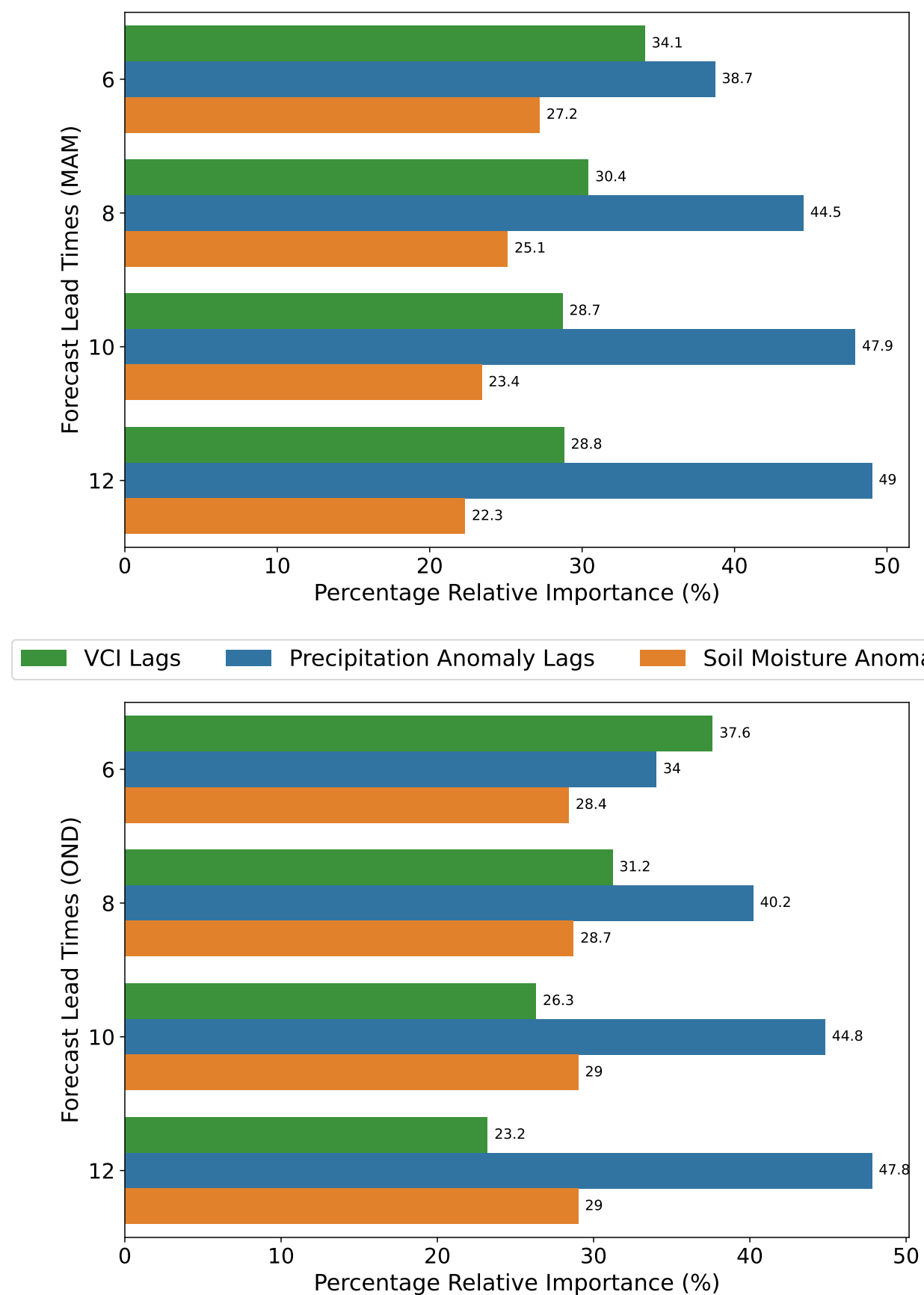

\section{VCl Lags}

Figure C1. Cumulative lag relative importance plots for counties for the MAM and OND Seasons. 


\section{Appendix D: Contour plots showing forecast performance for MAM and OND seasons}
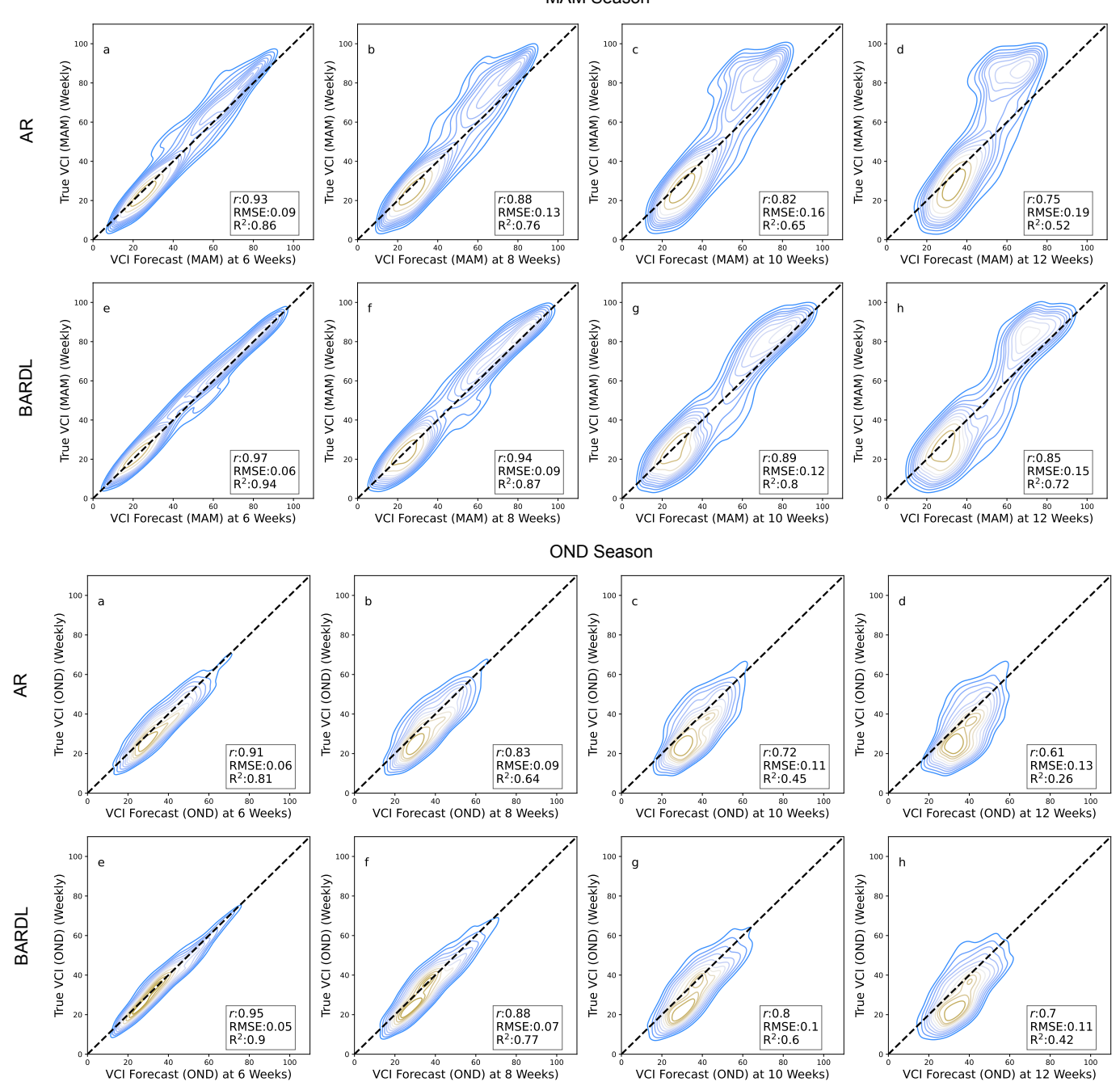

Figure D1. Contour plots showing VCI3M forecast against True VCI3M for MAM and OND Seasons. Plots (a,b,c,d) shows the results from the AR method with VCI3M only, (e,f,g,h) shows the overall results for BARDL modelled with lags of VCI3M plus lags of Precipitation (P3M) and Soil Moisture (S3M) Anomalies for 6, 8, 10 and 12 weeks lead time for all counties 
https://doi.org/10.5194/nhess-2021-223

Preprint. Discussion started: 16 August 2021

(c) Author(s) 2021. CC BY 4.0 License.

(c) (1)
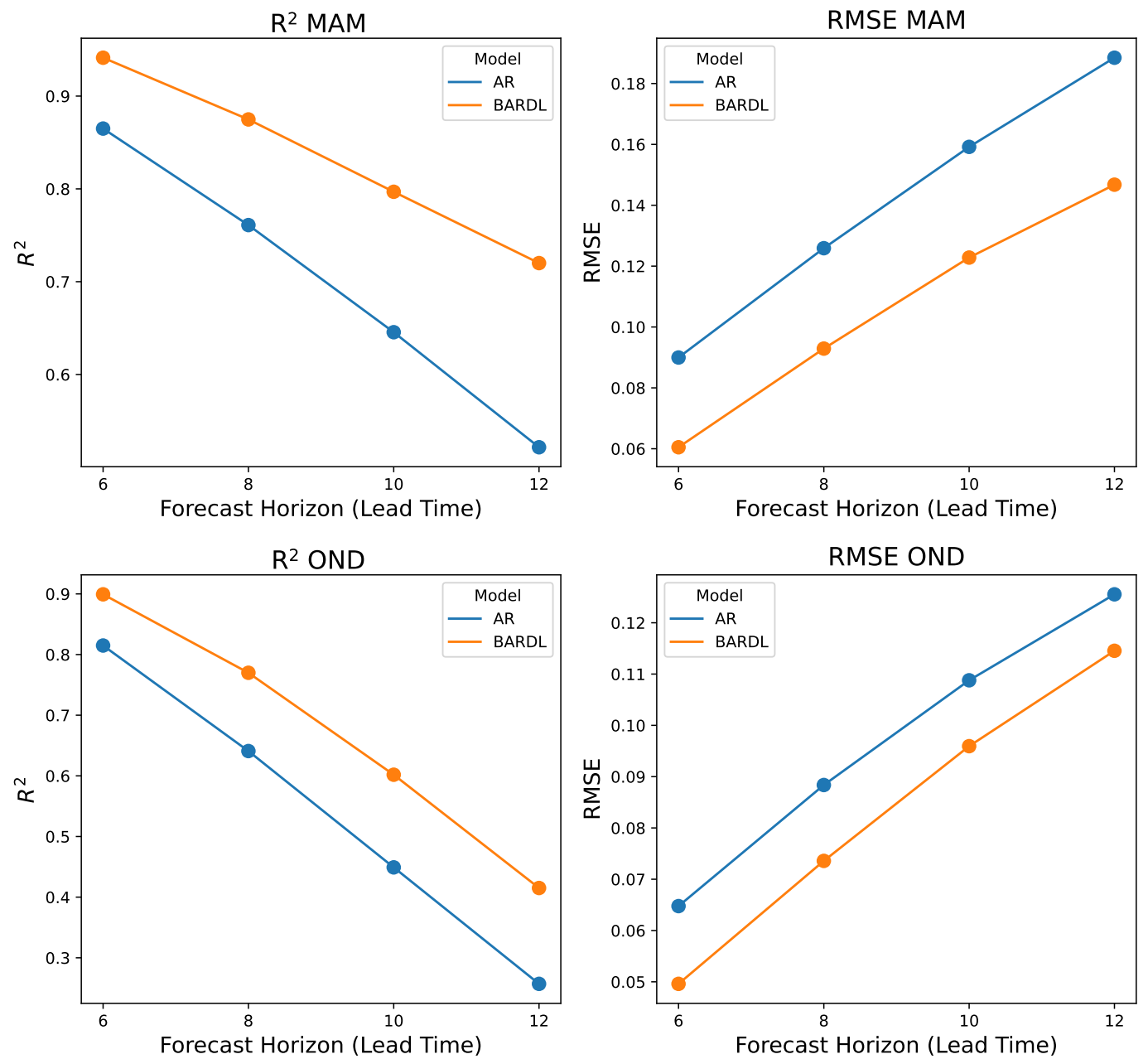

Figure E1. Performance metrics used to measure model accuracy as a function of forecast lead time for MAM and OND Season. 


\section{Appendix F: Forecast reliability for MAM and OND seasons}
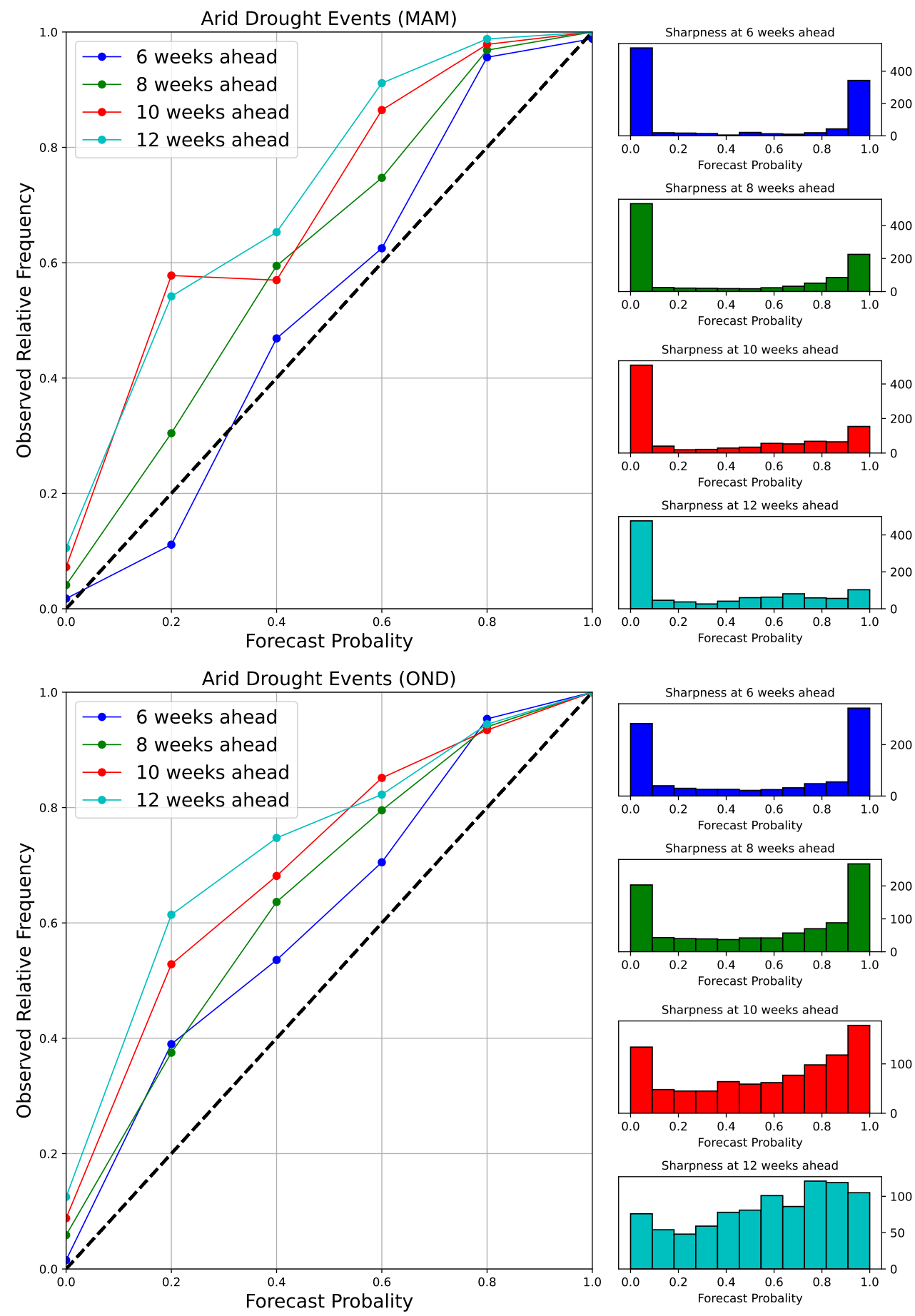

Figure F1. Reliability diagram showing forecast probability and their corresponding observed frequencies for 6, 8, 10, 12 weeks lead time together with their corresponding sharpness plots for drought events $(\mathrm{VCI} 3 \mathrm{M}<35)$ MAM and OND 
https://doi.org/10.5194/nhess-2021-223

Preprint. Discussion started: 16 August 2021

(C) Author(s) 2021. CC BY 4.0 License.

(c) (i)

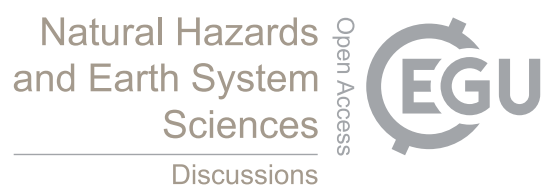

Author contributions. E.E.S. lead author, data preprocessing, modelling \& running BARDL method; J.M.M. data acquisition, preprocessing, cartography and feedback; A.B.B. code for AR method; A.B. code for smoothing time series data; S.O., P.R., \& P.H. conceptualised the initial idea and provided supervision and feedback; The final manuscript was edited and reviewed by all authors.

330 Competing interests. All authors of the paper declare no known competing interests (financial, personal relationships) that could have influenced this study.

Acknowledgements. The work was funded by the UK Newton Fund's Development in Africa with Radio Astronomy (DARA) Big Data project delivered via STFC with grant number ST/R001898/1 
https://doi.org/10.5194/nhess-2021-223

Preprint. Discussion started: 16 August 2021

(C) Author(s) 2021. CC BY 4.0 License.

\section{References}

Adede, C., Oboko, R., Wagacha, P., and Atzberger, C.: A mixed model approach to drought prediction using artificial neural networks: Case of an operational drought monitoring environment., arXiv Learning, pp. 1-18, https://doi.org/arXiv:1901.04927v1, 2019.

AghaKouchak, A.: A baseline probabilistic drought forecasting framework using standardized soil moisture index: Application to the 2012 United States drought, Hydrology and Earth System Sciences, 18, 2485-2492, https://doi.org/10.5194/hess-18-2485-2014, 2014.

Akaike, H.: Information theory and an extension of the maximum likelihood principle, in: Selected papers of hirotugu akaike, pp. 199-213, Springer, 1998.

Asaad, A.-a. B. and Magadia, J. C.: Stochastic Gradient Hamiltonian Monte Carlo on Bayesian Time Series Modeling, in: 14th National Convention on Statistics Crowne, 2019.

Barrett, A. B., Duivenvoorden, S., Salakpi, E. E., Muthoka, J. M., Mwangi, J., Oliver, S., and Rowhani, P.: Forecasting vegetation condition for drought early warning systems in pastoral communities in Kenya, Remote Sensing of Environment, 248, 111 886, 2020.

Ben Taieb, S. and Hyndman, R. J.: Recursive and direct multi-step forecasting: the best of both worlds, International Journal of Forecasting, 2014.

Ben Taieb, S., Sorjamaa, A., and Bontempi, G.: Multiple-output modeling for multi-step-ahead time series forecasting, Neurocomputing, 73, 1950-1957, https://doi.org/10.1016/j.neucom.2009.11.030, 2010.

Bradley, A. P.: The use of the area under the ROC curve in the evaluation of machine learning algorithms, Pattern Recognition, 30, 11451159, https://doi.org/https://doi.org/10.1016/S0031-3203(96)00142-2, 1997.

Cabot Venton, C., Fitzgibbon, C., Shitarek, T., Coulter, L., and Dooley, O.: Economics of Resilience Final Report The Economics of Early Response and Disaster Resilience: Lessons from Kenya and Ethiopia, Tech. rep., 2012.

Camberlin, P. and Wairoto, J. G.: Intraseasonal wind anomalies related to wet and dry spells during the "long"and "short"rainy seasons in Kenya, Theoretical and Applied Climatology, 58, 57-69, https://doi.org/10.1007/BF00867432, 1997.

Cenacchi, N.: Drought Risk Reduction in Agriculture: A Review of Adaptive Strategies in East Africa and the Indo-Gangetic Plain of South Asia, Browser Download This Paper, 2014.

Coughlan de Perez, E., van den Hurk, B., van Aalst, M. K., Jongman, B., Klose, T., and Suarez, P.: Forecast-based financing: an approach for catalyzing humanitarian action based on extreme weather and climate forecasts, Natural Hazards and Earth System Sciences, 15, 895-904, https://doi.org/10.5194/nhess-15-895-2015, 2015.

Deleersnyder, R.: Pastoralism in East Africa: challenges and solutions । Glo.be, https://www.glo-be.be/index.php/en/articles/ pastoralism-east-africa-challenges-and-solutions, 2018.

Dorigo, W., Wagner, W., Albergel, C., Albrecht, F., Balsamo, G., Brocca, L., Chung, D., Ertl, M., Forkel, M., Gruber, A., Haas, E., Hamer, P. D., Hirschi, M., Ikonen, J., de Jeu, R., Kidd, R., Lahoz, W., Liu, Y. Y., Miralles, D., Mistelbauer, T., Nicolai-Shaw, N., Parinussa, R., Pratola, C., Reimer, C., van der Schalie, R., Seneviratne, S. I., Smolander, T., and Lecomte, P.: ESA CCI Soil Moisture for improved Earth system understanding: State-of-the art and future directions, Remote Sensing of Environment, 203, 185-215, https://doi.org/10.1016/j.rse.2017.07.001, 2017.

Eilers, P. H. C.: A Perfect Smoother, Analytical Chemistry, 75, 3631-3636, https://doi.org/10.1021/ac034173t, pMID: 14570219, 2003.

FAO: Easing the impact of drought in Kenya : FAO in Emergencies, http://www.fao.org/emergencies/resources/photos/photo-detail/en/c/ $1053828 /, 2017$. 
https://doi.org/10.5194/nhess-2021-223

Preprint. Discussion started: 16 August 2021

(C) Author(s) 2021. CC BY 4.0 License.

FAO: Pastoralism in Africa's drylands Reducing risks, addressing vulnerability and enhancing resilience, Tech. rep., http://www.fao.org/3/ ca1312en/CA1312EN.pdf, 2018.

FEWSNET: Famine Early Warning Systems Network. FEWS NET., https://fews.net/, 2019.

Funk, C., Peterson, P., Landsfeld, M., Pedreros, D., Verdin, J., Shukla, S., Husak, G., Rowland, J., Harrison, L., Hoell, A., and Michaelsen, J.: The climate hazards infrared precipitation with stations - A new environmental record for monitoring extremes, Scientific Data, 2, 1-21, https://doi.org/10.1038/sdata.2015.66, 2015.

Gebremeskel, G., Tang, Q., Sun, S., Huang, Z., Zhang, X., and Liu, X.: Droughts in East Africa: Causes, impacts and resilience, https://doi.org/10.1016/j.earscirev.2019.04.015, 2019.

Gruber, A., Scanlon, T., Van Der Schalie, R., Wagner, W., and Dorigo, W.: Evolution of the ESA CCI Soil Moisture climate data records and their underlying merging methodology, Earth System Science Data, 11, 717-739, https://doi.org/10.5194/essd-11-717-2019, 2019.

Gujarati, D.: Basic Econometrics, Economic series, McGraw Hill, https://books.google.co.uk/books?id=byu7AAAAIAAJ, 2003.

Hoffman, M. D. and Gelman, A.: The no-U-turn sampler: Adaptively setting path lengths in Hamiltonian Monte Carlo, Journal of Machine Learning Research, 15, 1593-1623, 2014.

Hyndman, R. J. and Athanasopoulos, G.: Forecasting: principles and practice, OTexts, 2018.

Ji, L. and Peters, A. J.: Lag and seasonality considerations in evaluating AVHRR NDVI response to precipitation, Photogrammetric Engineering and Remote Sensing, 71, 1053-1061, https://doi.org/10.14358/PERS.71.9.1053, 2005.

Klisch, A. and Atzberger, C.: Operational drought monitoring in Kenya using MODIS NDVI time series, Remote Sensing, 8, https://doi.org/10.3390/rs8040267, 2016.

Kogan, F. N.: Application of vegetation index and brightness temperature for drought detection, Advances in Space Research, 15, 91-100, https://doi.org/10.1016/0273-1177(95)00079-T, 1995.

Lambert, B.: A Student's Guide to Bayesian Statistics, SAGE Publications, https://books.google.co.uk/books?id=ZvBUDwAAQBAJ, 2018.

Lei Ji and Peters, A. J.: Forecasting vegetation greenness with satellite and climate data, IEEE Geoscience and Remote Sensing Letters, 1, 3-6, https://doi.org/10.1109/LGRS.2003.821264, 2004.

Martin, O.: Bayesian Analysis with Python: Introduction to statistical modeling and probabilistic programming using PyMC3 and ArviZ, 2nd Edition, Packt Publishing, https://books.google.co.uk/books?id=1Z2BDwAAQBAJ, 2018.

McElreath, R.: Statistical Rethinking: A Bayesian Course with Examples in R and Stan, Chapman \& Hall/CRC Texts in Statistical Science, CRC Press, https://books.google.co.uk/books?id=1yhFDwAAQBAJ, 2016.

Milford, J. R. and Dugdale, G.: Monitoring of rainfall in relation to the control of migrant pests, Philosophical Transactions - Royal Society of London, B, 328, 689-704, https://doi.org/10.1098/rstb.1990.0137, 1990.

Neal, R. M.: Probabilistic inference using Markov chain Monte Carlo methods, Department of Computer Science, University of Toronto Toronto, Ontario, Canada, 1993.

Pang, J., Liu, D., Peng, Y., and Peng, X.: Optimize the coverage probability of prediction interval for anomaly detection of sensor-based monitoring series, Sensors (Switzerland), 18, https://doi.org/10.3390/s18040967, 2018.

Pesaran, M. H. and Shin, Y.: An Autoregressive Distributed-Lag Modelling Approach to Cointegration Analysis, p. 371-413, Econometric Society Monographs, Cambridge University Press, https://doi.org/10.1017/CCOL521633230.011, 1999.

Quiring, S. M. and Ganesh, S.: Evaluating the utility of the Vegetation Condition Index (VCI) for monitoring meteorological drought in Texas, Agricultural and Forest Meteorology, 150, 330-339, https://doi.org/https://doi.org/10.1016/j.agrformet.2009.11.015, 2010. 
https://doi.org/10.5194/nhess-2021-223

Preprint. Discussion started: 16 August 2021

(c) Author(s) 2021. CC BY 4.0 License.

(c) (1)

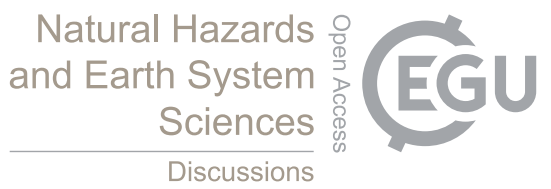

Rippa, S.: An algorithm for selecting a good value for the parameter c in radial basis function interpolation, Advances in Computational Mathematics, 11, 193-210, https://doi.org/10.1023/A:1018975909870, 1999.

Robert, C. P., Elvira, V., Tawn, N., and Wu, C.: Accelerating MCMC algorithms, Wiley Interdisciplinary Reviews: Computational Statistics, 410 10, e1435, https://doi.org/10.1002/WICS.1435, 2018.

Salvatier, J., Wiecki, T. V., and Fonnesbeck, C.: Probabilistic programming in Python using PyMC3, PeerJ Computer Science, 2, e55, 2016.

Schaaf, C. and Wang, Z.: MCD43A4 MODIS/Terra+Aqua BRDF/Albedo Nadir BRDF Adjusted Ref Daily L3 Global - 500m V006 [Data set], https://doi.org/10.5067/MODIS/MCD43A4.006, 2015.

Sibanda, M., Mutanga, O., Rouget, M., and Kumar, L.: Estimating biomass of native grass grown under complex management treatments using worldview-3 spectral derivatives, Remote Sensing, 9, https://doi.org/10.3390/rs9010055, 2017.

Su, D., Ting, Y. Y., and Ansel, J.: Tight Prediction Intervals Using Expanded Interval Minimization, http://arxiv.org/abs/1806.11222, 2018.

Tonidandel, S. and LeBreton, J. M.: Relative importance analysis: A useful supplement to regression analysis, Journal of Business and Psychology, 26, 1-9, 2011.

UNFCCC: ADOPTION OF THE PARIS AGREEMENT - Paris Agreement text English, Tech. rep., 2015.

Vatter, J.: DROUGHT RISK The Global Thirst for Water in the Era of Climate Crisis, Tech. rep., World Wildlife Fund (WWF) Germany, www.studioazola.com, 2019.

Vicente-Serrano, S. M.: Evaluating the impact of drought using remote sensing in a Mediterranean, Semi-arid Region, Natural Hazards, 40, 173-208, https://doi.org/10.1007/s11069-006-0009-7, 2007.

Wilks, D.: Statistical methods in the atmospheric sciences, 2006.

WWRP: World Weather Research Programme (WWRP), Forecast Verification - Methods and FAQ, https://www.cawcr.gov.au/projects/ verification/verif_web_page.html, 2009.

Yang, Y., Xiao, P., Feng, X., and Li, H.: Accuracy assessment of seven global land cover datasets over China, ISPRS Journal of Photogrammetry and Remote Sensing, 125, 156-173, https://doi.org/10.1016/j.isprsjprs.2017.01.016, 2017. 


\section{List of Figures}

1 A map of Kenya showing the arid and semi-arid counties where the research was focused. . . . . . . . . . . 3

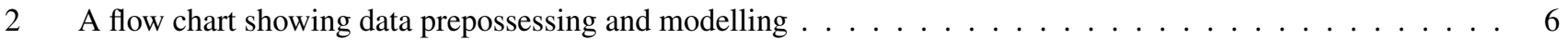

3 Contour plots showing VCI3M forecast against True VCI3M. Plots (a,b,c,d) shows the results from the AR method with VCI3M only, (e,f,g,h) shows the overall results for BARDL modelled with lags of VCI3M plus lags of Precipitation (P3M) and Soil Moisture (S3M) Anomalies for 6, 8, 10 and 12 weeks lead time for all counties .

4 Performance metrics used to measure model accuracy as a function of forecast lead time. $R^{2}$ (Left), RMSE (Right).

5 Time series plot showing uncertainty for 6, 8, 10,12 weeks lead time for Mandera county. Plots on the left side are from the AR model and plots to the right are BARDL. The PICP and MPIW for the other counties can

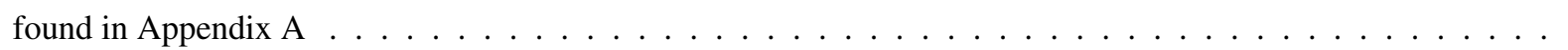

6 ROC Curve showing True Positive Rate (TPR), False Positive Rates(FPR) and AUC for 6,8,10,12 weeks for both AR (Dotted line) and BARDL (Solid line) forecasts. The VCI3M $<35$ threshold is plotted as points on

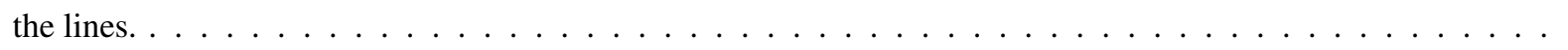

7 Reliability diagram showing forecast probability and their corresponding observed frequencies for $6,8,10,12$ weeks lead time together with their corresponding sharpness plots for drought events $(\mathrm{VCI} 3 \mathrm{M}<35)$ in the arid and semi-arid counties $\ldots \ldots \ldots \ldots \ldots \ldots \ldots \ldots \ldots$

8 Bar plots showing the cumulative (All lags) relative importance of additional variables to the VCI3M forecast for all counties $\ldots \ldots \ldots \ldots \ldots \ldots \ldots \ldots \ldots \ldots \ldots \ldots \ldots$

B1 Relative Importance for each exogenous factors for each lag $(0-5)$ variable per county. . . . . . . . . . . . 22

C1 Cumulative lag relative importance plots for counties for the MAM and OND Seasons.

D1 Contour plots showing VCI3M forecast against True VCI3M for MAM and OND Seasons. Plots (a,b,c,d) shows the results from the AR method with VCI3M only, (e,f,g,h) shows the overall results for BARDL modelled with lags of VCI3M plus lags of Precipitation (P3M) and Soil Moisture (S3M) Anomalies for 6, 8, 10

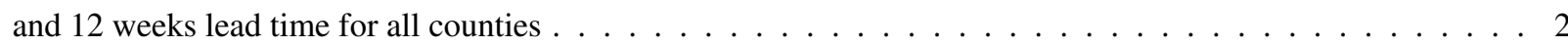

455 E1 Performance metrics used to measure model accuracy as a function of forecast lead time for MAM and OND Season.

F1 Reliability diagram showing forecast probability and their corresponding observed frequencies for $6,8,10,12$ weeks lead time together with their corresponding sharpness plots for drought events ( $\mathrm{VCI} 3 \mathrm{M}<35) \mathrm{MAM}$ and OND . 
https://doi.org/10.5194/nhess-2021-223

Preprint. Discussion started: 16 August 2021

(C) Author(s) 2021. CC BY 4.0 License.

(c) (1)

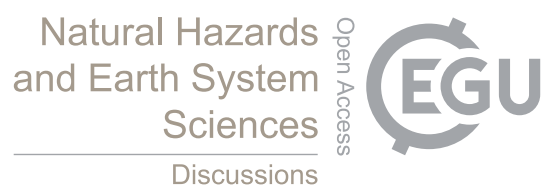

$2 \quad \mathrm{R}^{2}$ scores (6 to 12 weeks lead times) for AR modelled with lags of VCI3M only, BARDL modelled with lags of VCI3M with Precipitation (P3M) and Soil Moisture (SM3M) for arid and semi-arid counties. . . . . . . . 13

A1 The PICP and MPIW (in parenthesis ) estimates for the all arid and semi-arid counties. . . . . . . . . . . . 20 